University of Louisville

ThinkIR: The University of Louisville's Institutional Repository

Electronic Theses and Dissertations

$5-2012$

\title{
Maximum power point tracker for solar arrays using controlled rectifier.
}

Anvin Joe Manadan 1987-

University of Louisville

Follow this and additional works at: https://ir.library.louisville.edu/etd

\section{Recommended Citation}

Manadan, Anvin Joe 1987-, "Maximum power point tracker for solar arrays using controlled rectifier."

(2012). Electronic Theses and Dissertations. Paper 896.

https://doi.org/10.18297/etd/896

This Master's Thesis is brought to you for free and open access by ThinkIR: The University of Louisville's Institutional Repository. It has been accepted for inclusion in Electronic Theses and Dissertations by an authorized administrator of ThinkIR: The University of Louisville's Institutional Repository. This title appears here courtesy of the author, who has retained all other copyrights. For more information, please contact thinkir@louisville.edu. 


\title{
MAXIMUM POWER POINT TRACKER FOR SOLAR ARRAYS USING CONTROLLED RECTIFIER
}

\author{
By \\ Anvin Joe Manadan \\ B-Tech, Cochin University of Science and Technology, 2009
}

\author{
A Thesis \\ Submitted to the Faculty of the \\ I.B. Speed School of Engineering \\ in Partial fulfillment of the requirements \\ for the Degree of \\ Master of Science \\ Electrical and Computer Engineering Department \\ University of Louisville \\ Louisville, Kentucky
}

May 2012 


\title{
MAXIMUM POWER POINT TRACKER FOR SOLAR ARRAYS USING CONTROLLED RECTIFIER
}

\author{
By \\ Anvin Joe Manadan \\ B-Tech, Cochin University of Science And Technology, 2009
}

A Thesis Approved on

January 11, 2012

By the following Thesis Committee:

Dr. Michael L. McIntyre

Thesis Advisor

Dr. John F. Naber

Dr. Adel Elmaghraby 


\section{DEDICATION}

This thesis is dedicated to my family members

Mr. Joe V. Manadan

Mrs. Geetha Joe

Mr. Arun J. Manadan

Who have been constant sources of inspiration. 


\section{ACKNOWLEDGEMENTS}

I would like to express my sincere gratitude to Dr. Michael L. McIntyre for his continuous support and inspiration. I always felt a good level of friendship and cooperation besides being a student. I would like to thank Dr. John F. Naber for his guidance and valuable suggestions throughout my studies. I would also like to thank him for the engineering experience that I gained from working with him. I would like to extend my heartfelt gratitude to Dr. Adel Elmaghraby for his valuable suggestions to make this thesis more effective. Finally, I would like to thank my family and friends for their patience and support throughout my studies. 


\section{ABSTRACT \\ MAXIMUM POWER POINT 'TRACKER FOR SOLAR ARRAYS USING CONTROLLED RECTIFIER}

\section{Anvin Joe Manadan}

\section{January 11, 2012}

Solar energy offers a large potential as a source of energy and in light of financial and ethical reasons, people are looking to harvest it for their energy needs. The conversion of solar energy to electricity is performed by solar cells. There exists an operating point associated with solar cells at which the power generated is maximized at any given point in time. A maximum power point tracker (MPPT) is required to track this maximum power operating point (MPOP). A wide range of systems exists to meet this purpose. This thesis explores the use of a single-phase controlled rectifier, with backstepping control to track the maximum power from a string of solar arrays. This controller tracks the MPOP using a circuit topology that has been under investigation within the literature and was simulated using MATLAB/Simulink. Simulation results showed that the designed converter and control strategy could transfer power from a string of solar arrays to the grid by efficiently tracking the MPOP. 


\section{TABLE OF CONTENTS}

PAGE

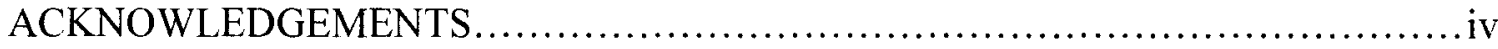

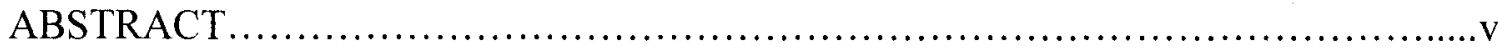

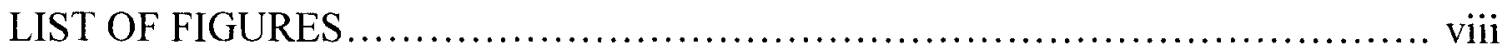

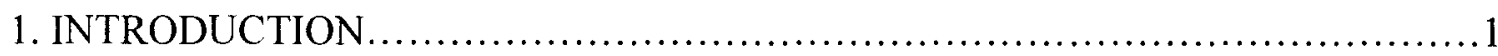

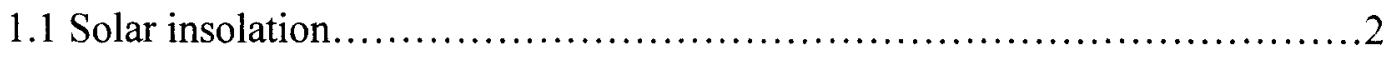

1.2 Solar cell............................................................ 4

1.3 Solar modules for commercial use ...................................

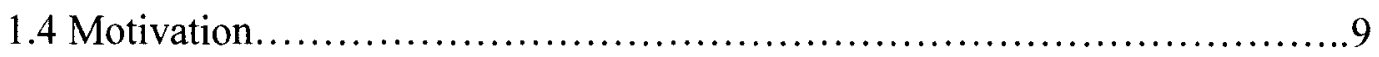

1.5 Background .......................................................... 11

1.5.1 Perturb and observe algorithm.................................12

1.5.2 Sliding-Mode Observer.......................................14

1.5.3 Voltage feedback method...................................... 15

1.5.4 Fuzzy logic control........................................ 16

1.6 Thesis organization...................................................... 17

2. PV ENERGY SYSTEM ........................................................ 19

2.1 Array dynamics..................................................... 19

2.2 Array parameters................................................. 21

2.3 Converter....................................................... 23

2.3.1 Controlled rectifier operation...................................24

2.3.2 Circuit Dynamics............................................ 28

2.4 Trajectory generation algorithm........................................ 31

2.5 Controller design...................................................... 35 
2.5.1 Error system development............................. 35

2.6 Stability analysis............................................... 37

2.6.1 Proof............................................................ 37

3. RESULTS AND CONCLUSIONS ...................................... 40

3.1 Simulation results......................................... 41

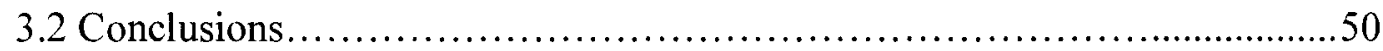

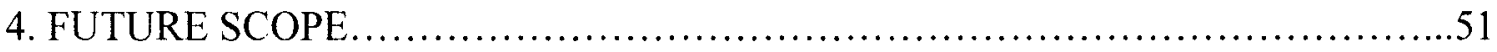

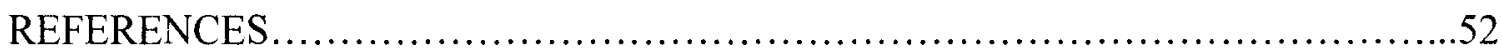

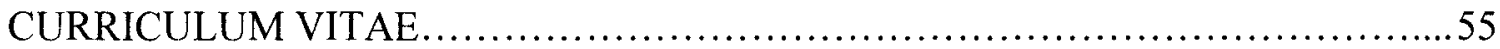




\section{LIST OF FIGURES}

FIGURE PAGE

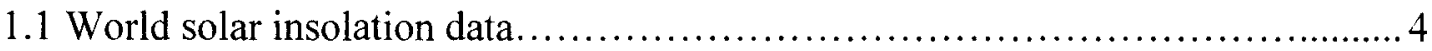

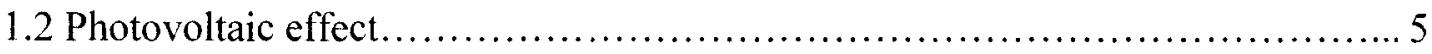

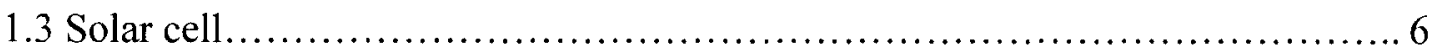

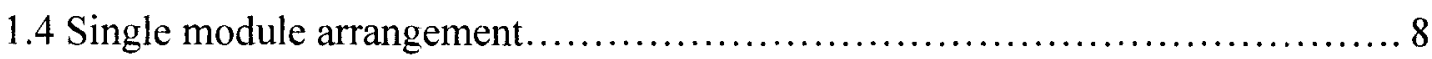

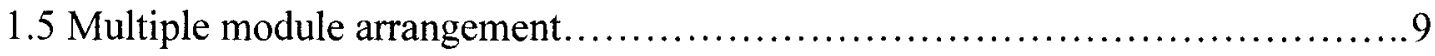

1.6 Four block model of energy conversion system............................ 11

1.7 Perturb and observe algorithm.......................................... 13

1.8 Oscillations at maximum power point ...................................... 13

1.9 Sliding-Mode observer system............................................... 14

1.10 Look up table of fuzzy logic controller.................................... 16

2.1 Current-voltage characteristics of solar array .................................. 20

2.2 Power-voltage characteristics of solar array ................................. 21

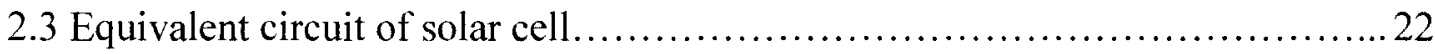

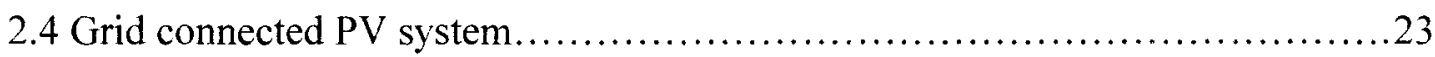

2.5 Positive half-cycle operation............................................... 24

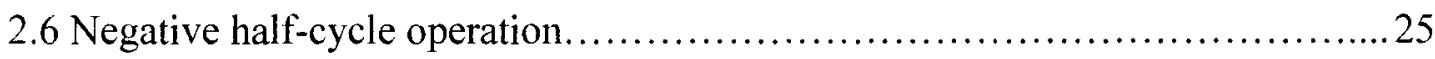

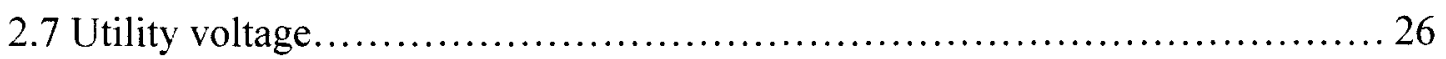

2.8 Rectifier output voltage.................................................. 26

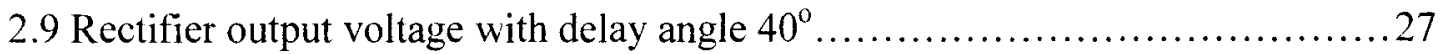

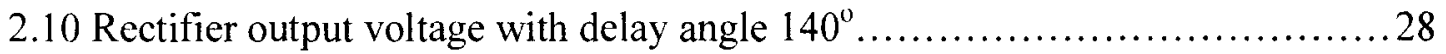

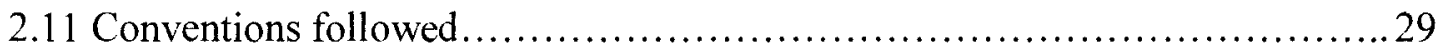

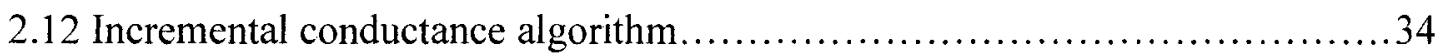




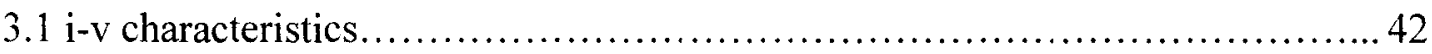

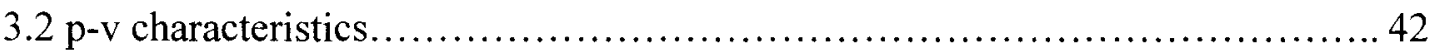

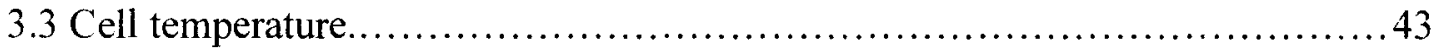

3.4 Solar radiation ............................................................... 43

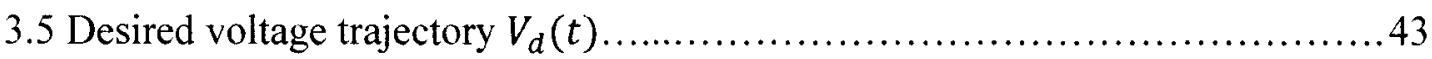

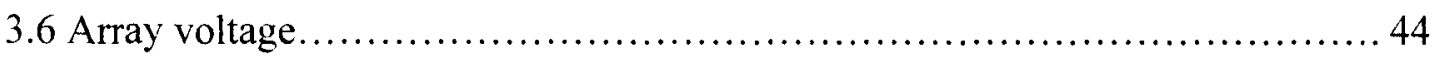

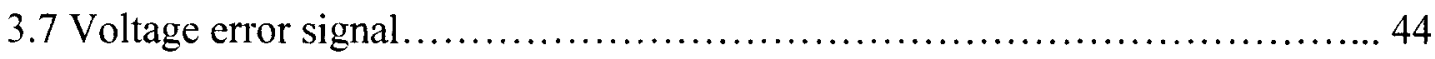

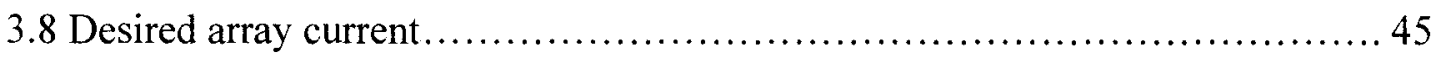

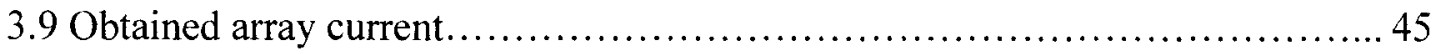

3.10 Current error signal........................................................... 46

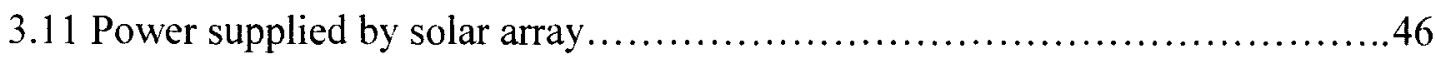

3.12 Power loss across resistor...................................................... 47

3.13 Ac output power........................................................... 48

3.14 Comparison graph............................................................. 48

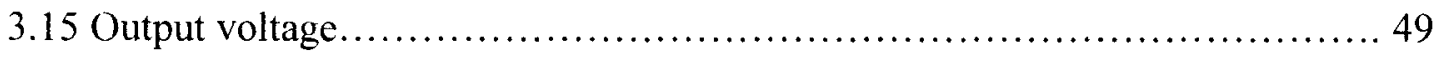

3.16 Magnified output voltage ................................................. 49

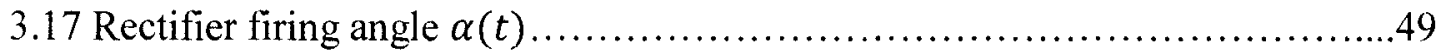

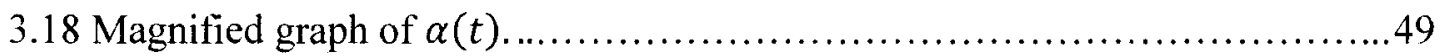




\section{CHAPTER 1}

\section{INTRODUCTION}

The energy requirements of the world population has been continuously increasing and is expected to increase at a higher rate in future. Fossil fuels have been supplying the major part of the energy requirements over the centuries and continues to be a major contributor. As the fossil fuel reserves are becoming exhausted and due to increasing environmental issues, people are more concerned over their usage. A solution to these issues is to reduce the dependence on fossil fuels and utilize renewable sources of energy as they are inexhaustive and cause less pollution when compared to fossil fuels. Statistics show that the share of renewable power in global energy consumption reached $1.3 \%$ in 2010 , up from $0.6 \%$ in 2000 . Renewable sources include solar energy, wind energy, geothermal energy, tidal energy etc., of which solar energy is the focus in this thesis. Solar energy can be defined as the energy from sun that can be converted into other forms of energy such as thermal or electrical energy.

Ancient civilizations used solar energy for various purposes. The Egyptians utilized sunlight to heat their homes by capturing the energy in black pools of water during day time and draining the hot water into pipes below the floor. Ancient 
Greeks designed their homes oriented to the sun to use sunlight to heat their homes during winter. Another prominent use of solar energy was to provide a hot water supply during winter. The nineteenth century witnessed the use of solar energy to operate water pumps and steam engines. These facts conclude that solar energy is not new and is a well proven technology. Some of the factors that make solar energy stand out from other sources of energy are:

- The power source is absolutely free of cost.

- Conversion of solar energy to other forms of energy does not cause pollution.

- Energy conversion systems have a lifespan of 30 to 40 years with very little maintenance.

- These systems have a full warranty for 20 to 30 years or more.

- Advancements in technology have improved the conversion efficiency of these systems. Typical efficiency for modern systems is around 15\% [21].

- Government provide subsidies and tax exemptions to encourage the use of solar energy.

In addition, solar energy systems reduce the stress on electrical grids by providing an extra source of power. In par with these advantages, solar energy has disadvantages with cost being the major one. However, with support from government in the form of subsidies and tax exemptions along with advancements in technology, solar energy stands out to be a cost effective and promising solution to the world's energy requirements.

\subsection{Solar insolation}


Insolation is a measure of solar radiation received on a given surface area in a given time. It is commonly expressed as average irradiance in watts per square meter $\left(\mathrm{W} / \mathrm{m}^{2}\right)$. When sunlight strikes a surface, part of energy contained is absorbed, while the remainder is reflected. The absorbed energy is converted into other forms of energy such as thermal or electrical energy. Plants utilize sunlight during photosynthesis to prepare organic compounds which are stored inside their bodies. Based on regular readings from NASA's Solar Radiation and Climate Experiment (SORCE) satellite, the total solar irradiance upon Earth was measured to be roughly $1,361 \mathrm{~W} / \mathrm{m}^{2}$ [20]. The sun's rays get attenuated as they pass through the Earth's atmosphere and upon reaching the Earth's surface, the total solar irradiance is reduced to roughly $1,000 \mathrm{~W} / \mathrm{m}^{2}$ [20]. This figure varies with sun angle at different times of the year and also with atmospheric haze and cloud cover. Figure 1.1 [19] shows the variation of solar radiation received across the globe. Regions that are perpendicular to the sun's rays at sea level receive higher insolation when compared with other regions. Insolation is an important consideration when designing buildings for a particular region. Buildings are designed with large vertical windows on the equator-facing side. This helps in keeping the building warm in winter and cool in summer. Insolation figures are also used as an input when designing buildings, to size the solar power systems to be installed in a location.

One of the major ways to utilize solar energy is to employ solar cells and convert solar radiation into electricity. Conversion of solar energy into electricity is performed by a Photo Voltaic (PV) system. The system consists of PV modules, mechanical mountings, electrical connections and a mechanism to control output current. PV systems can be stand-alone or grid-connected. 


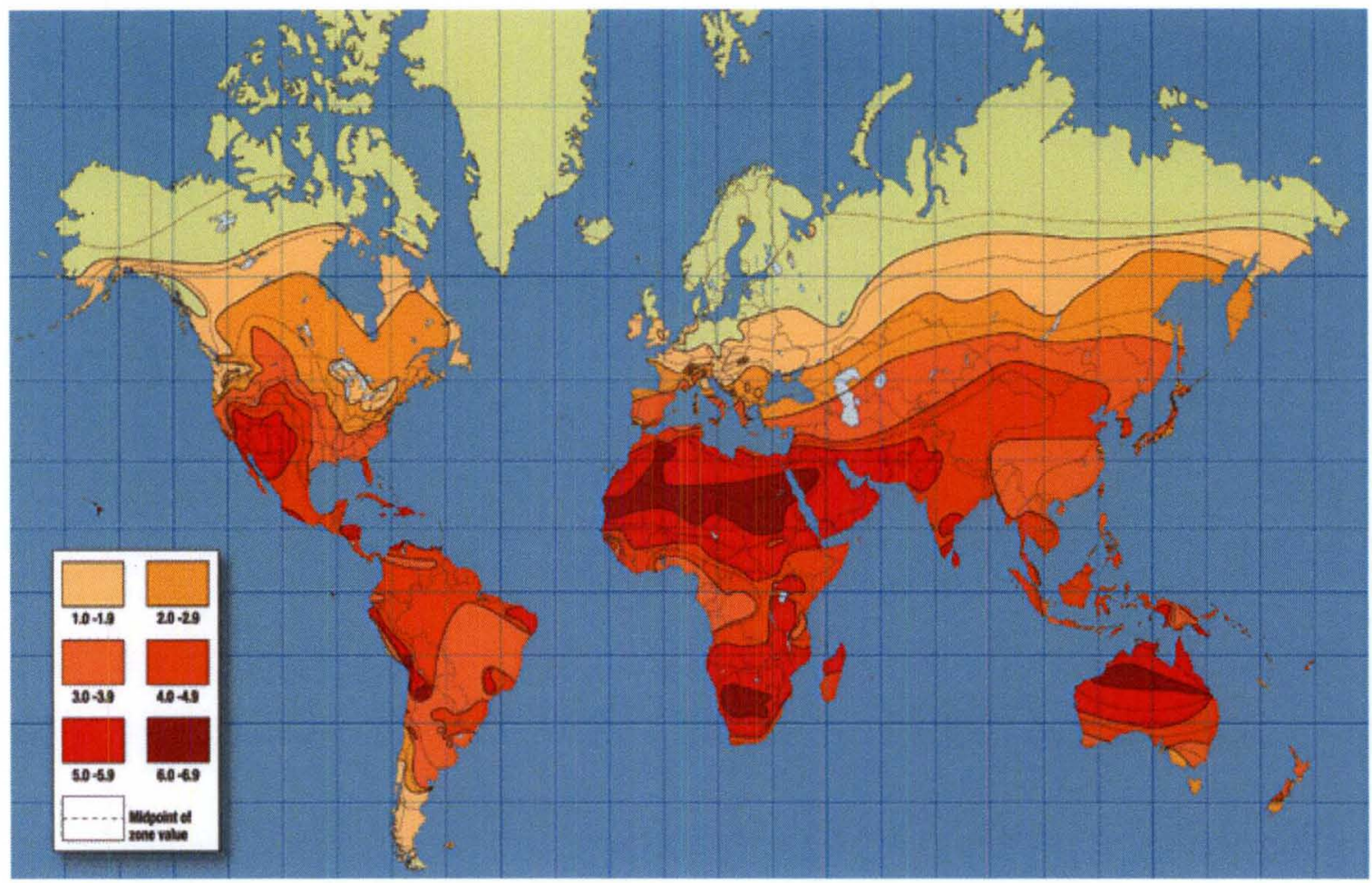

Figure 1.1: World solar insolation data

In the case of the stand-alone systems, the function of the control mechanism is to avoid excessive charging or discharging of battery; while in the case of the grid-connected system, its function is to track the maximum power from solar arrays. Conversion of solar radiation to electricity in a PV system is performed by solar cells and one type of solar cell is a solid state electrical device that is discussed in the following section.

\subsection{Solar cell}

A solar cell is a device that converts light energy into electricity. One type of it is a p-n semiconductor junction whose energy conversion is based on the principle of the photovoltaic effect, according to which build up of voltage occurs when electrons are transferred from the valence to conduction band in a semiconductor material. This effect was discovered by A. E. Becquerel, a French physicist in 1839. The movement of 
electrons is caused by the photons present in sunlight. The photons contain different amounts of energy that correspond to different wavelengths of the solar spectrum. When photons strike a PV cell, some are reflected, some pass through and some are absorbed by the cell. Energy of photons that is absorbed by the cell gets transferred to electrons in the atoms of semiconductor device. With this new energy, electrons escape from their normal positions to become part of the current in an electrical circuit. This phenomenon is shown in Figure 1.2 [23].

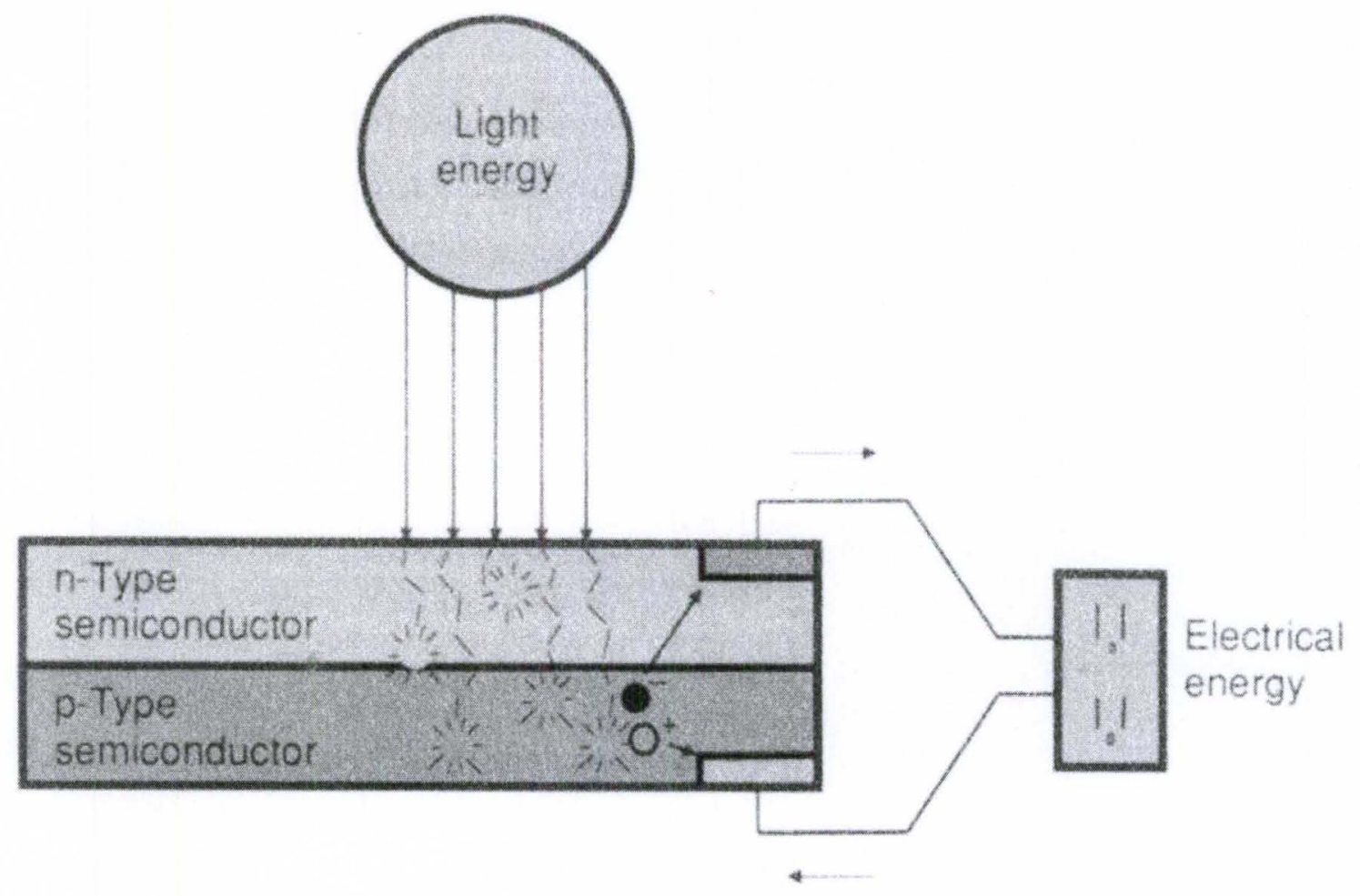

Figure 1.2: Photovoltaic effect

The PV cell is a variable source of power whereas sources such as battery provide constant power. Initially, solar cells were developed with platinum or selenium with an extremely thin layer of gold to form the junction. This device was only $1 \%$ efficient and was not used for practical applications. As the development of silicon progressed in the 
twentieth century, studies were conducted to use silicon for constructing solar cells. In 1954, the first silicon-based solar cell was developed at Bell Laboratories and this laid the road for decades of research. The cells were efficient and were initially used in toys and other minor applications as the cost of electricity they produced was relatively high. Figure 1.3 [27] shows the image of a solar cell constructed using monocrystalline silicon wafer. Other materials used to make solar cells include polycrystalline silicon, amorphous silicon, cadmium telluride and copper indium selenide.

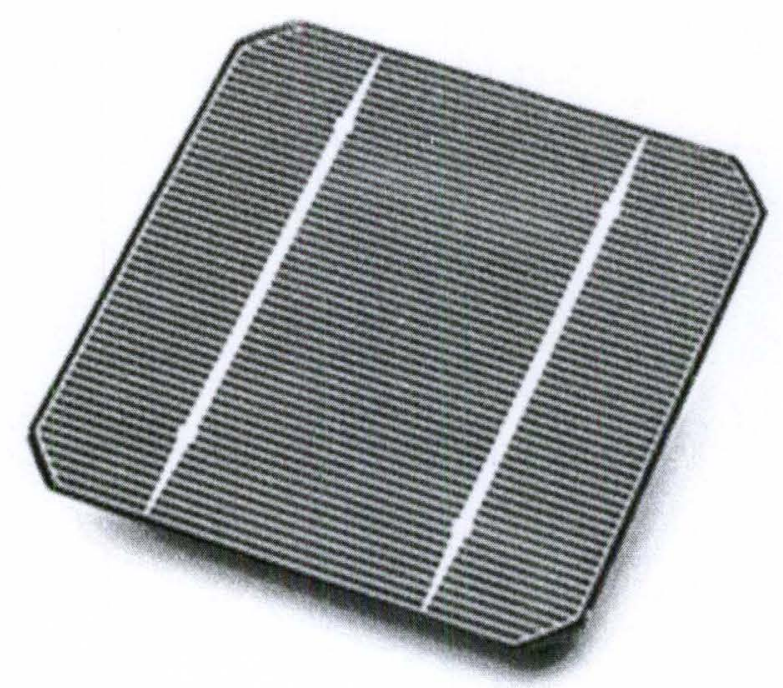

Figure 1.3: Solar cell

In 1958, suggestions were made to include solar cells in space applications, particularly in satellite spacecrafts. The main reason for this is that the satellites are nonserviceable systems that need a source of power throughout their mission and solar cells could perform this function. Since then, the use of solar cells in space technology became popular and millions of dollars were spent on research. The research was mainly to improve conversion efficiency of cells and presently, PV cells is the primary source of power for geo-stationary earth orbit or low Earth orbit satellites. 
Conversion efficiency of a solar cell is the percentage of incident light energy that actually ends up as electric power. It may be broken down into thermodynamic efficiency, reflectance efficiency, conductive efficiency and charge carrier separation efficiency. Overall efficiency is the product of each of these efficiencies. This mainly depends on the material used and has been approaching the theoretical limiting efficiency of $37.7 \%$ for single layer solar cells and $86 \%$ for multiple layer solar cells. Even with the improved efficiency, the power generated by an individual cell is comparatively low and not sufficient for practical uses. To improve the voltage and current ratings, cells are first connected in series to obtain the desired voltage and then connected in parallel to allow the system to produce the desired current. Such a series-parallel combination of solar cells is called a solar array. Solar arrays cannot produce electricity from the entire solar range that includes ultraviolet, infrared and diffused light. Depending on construction, they utilize a range of frequencies of light to generate electricity.

\subsection{Solar modules for commercial use}

A solar module is a packaged assembly of solar cells. They are used for commercial power generation and have 60 or more solar cells connected in a series combination. Such a module has a power rating of $200-300 \mathrm{~W}$ and a voltage rating of $30-$ $40 \mathrm{~V} \mathrm{DC}$. The module is connected to an inverter to transfer the power generated to grid. The inverter section includes a maximum power point (MPP) tracking algorithm and a tracking controller. The size of the inverter depends on the required power rating. For power requirements of the order of a few hundred watts, a single module with a micro level inverter is used. This is shown in Figure 1.4. 


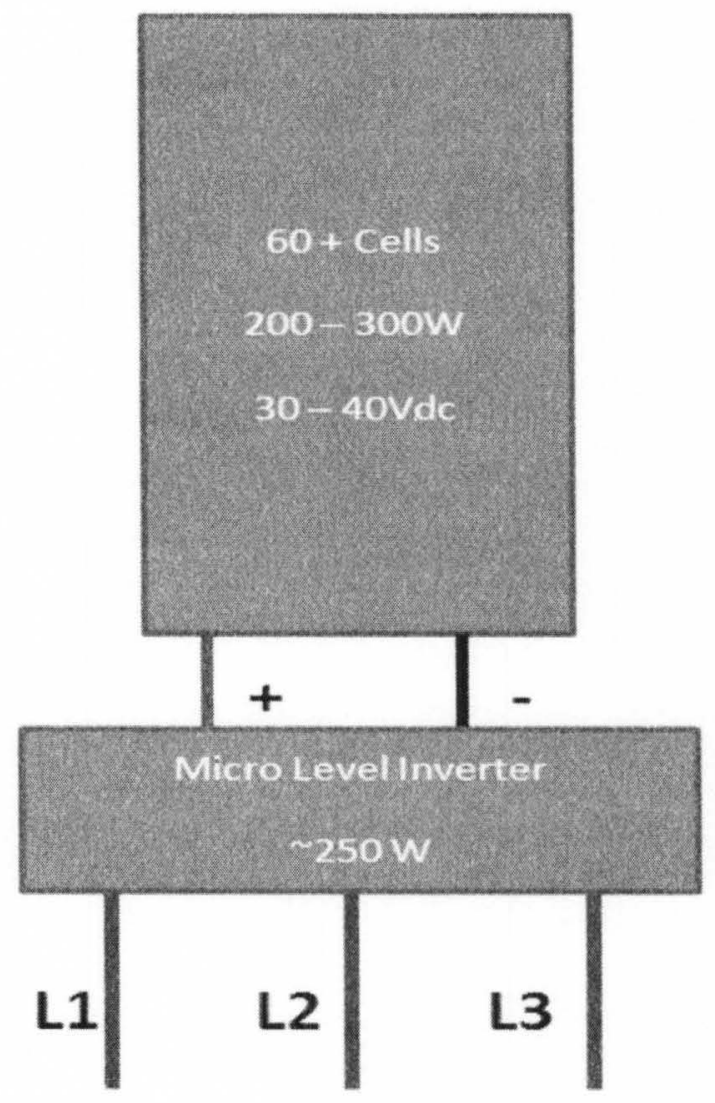

Figure 1.4: Single module arrangement

Power requirements above $300 \mathrm{~W}$ requires a string of solar panels that are connected together in a series-parallel combination. Figure 1.5 shows such an arrangement with four solar modules connected in series. In this case, a string level inverter is used to transfer power to a grid. The system discussed in this thesis employs such a system with multiple modules to generate the required power levels. 


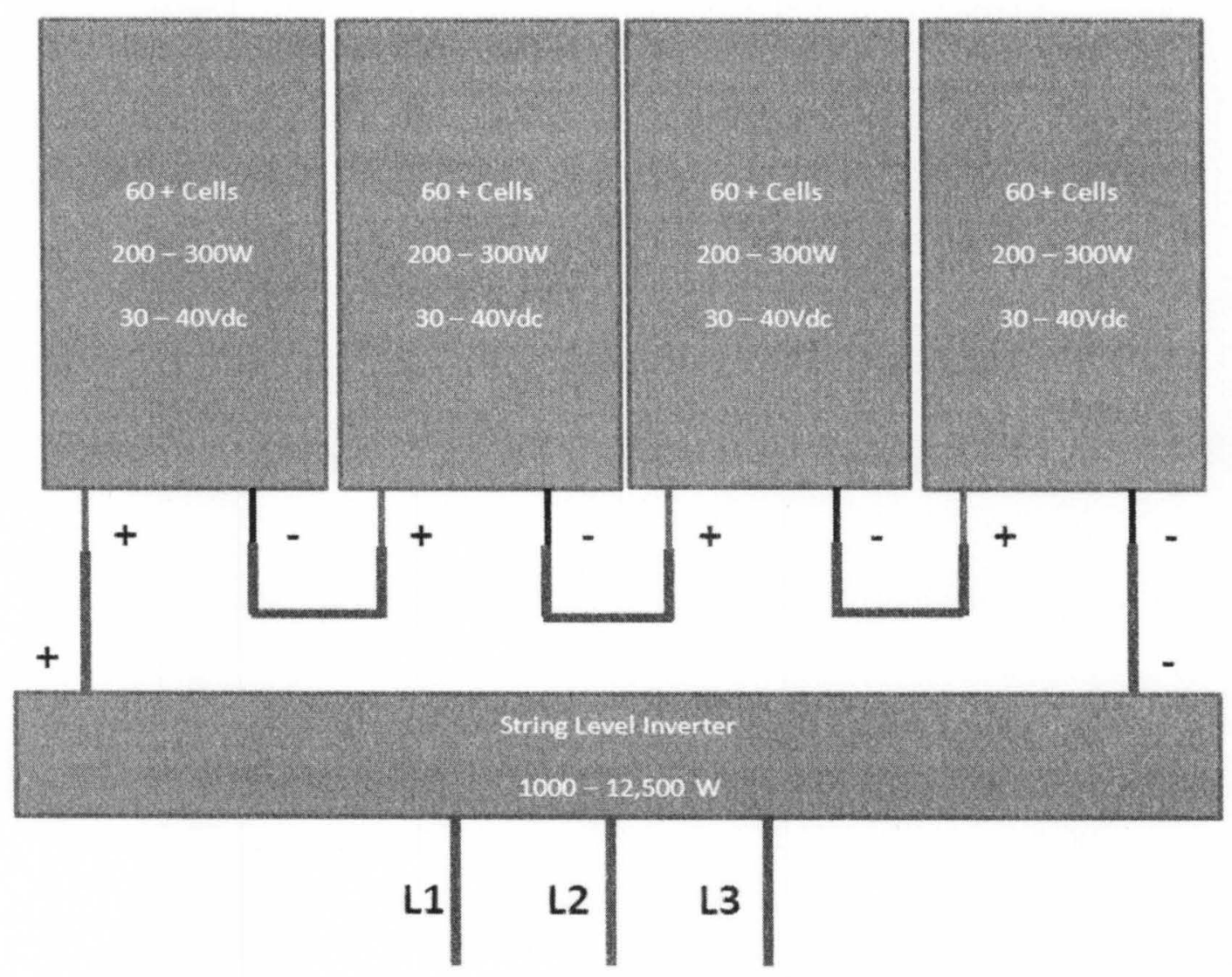

Figure 1.5: Multiple module arrangement

\subsection{Motivation}

Solar modules are used to generate electricity from solar energy. The solar cells that perform the energy conversion have a highly non-linear nature. In addition to this, the power generated by a solar cell varies with cell temperature and atmospheric conditions. Studies have shown that at each instant, there exists a maximum power operating point (MPOP) associated with a solar cell at which the power transferred is maximized. Thus, to track maximum power from solar arrays, the cell operating point needs to be close to the MPOP. A maximum power point tracker (MPPT) performs this function by employing a converter circuit and a control system. 
Various factors such as tracking speed and reduced oscillations at MPOP are critical to a good design. Some of the important factors considered while choosing the technique to perform MPP tracking are:

- Sensors used - The number of sensors affect the system's complexity and accuracy. As the number increases, tracking is done with more precision but with a higher complexity.

- Cost involved - Cost of the system is determined by resources required to implement the technique.

- Convergence speed - Convergence speed depends on the time taken by the system to converge to the required operating point. For a high performance tracking system, the time should be low.

- Ability to detect multiple maxima - The technique should be able to identify the true MPOP from multiple maxima. Multiple maxima occur due to variation in irradiance levels at different points on a solar panel surface and also due to broken cells in a panel. Efficiency and complexity of algorithm determine if the calculated maxima is a local MPP or true MPP.

Some of the approaches involve changing array configuration to match the load, while others depend on selection of PV module characteristics to suit the load. Efficiency of these systems drops in cases of rapidly changing atmospheric conditions. The reason for this is that these techniques are associated with specific atmospheric conditions, when these conditions change, efficiency drops. The PV systems developed so far follow a four block model, shown in Figure 1.6, to meet the purpose. The four blocks are: solar panel, trajectory generator, controller and converter. The trajectory generator develops the 
desired array voltage trajectory using a MPP tracking algorithm. The input to the algorithm is array parameters such as current and voltage. The generated voltage closely follows the MPOP and is given as input to the voltage tracking controller. The controller generates control signals to make the array voltage track the generated MPOP voltage trajectory. The converter is responsible for transferring the power generated by solar panel to the load.

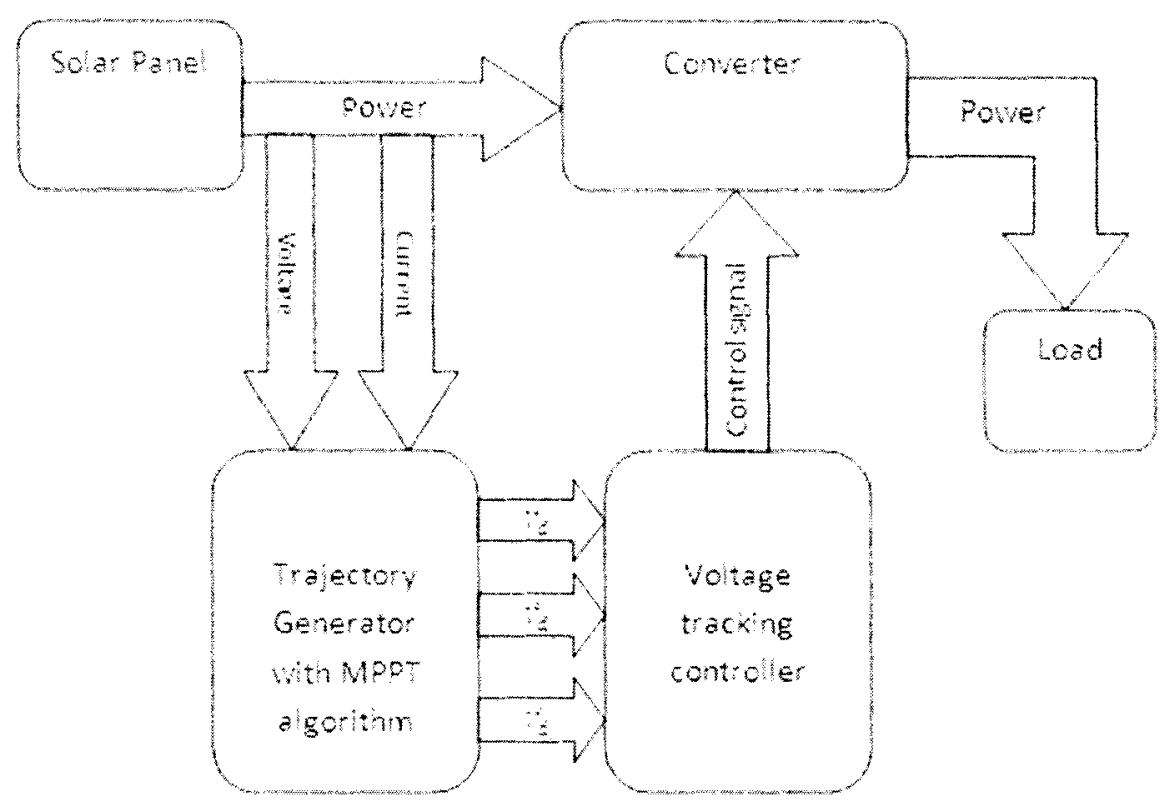

Figure 1.6: Four block model of energy conversion system

This thesis explores a new approach towards designing a MPPT that can efficiently track the MPOP under varying atmospheric conditions. The tracking system is described in detail in Chapter 2.

\subsection{Background}


To this end, several approaches have been developed to meet the MPP tracking objective for PV systems. Approaches differ in the control algorithm employed to track MPOP and also in converters that transfer power from solar arrays to battery or grid. Some of the approaches include perturbation method, single-phase inverter using slidingmode observer [7], DC-to-DC boost converter using backstepping pulse width modulation (PWM) control [11] and DC-to-DC boost converter using fuzzy neural network [5]. Although the performance of these approaches are satisfactory, it drops noticeably in cases of rapidly changing atmospheric conditions. Also, most of the converters give $\mathrm{DC}$ output which needs to be converted to $\mathrm{AC}$ prior to usage by the grid. Most of the MPP tracking algorithms use array terminal voltage as the control variable and involves continuous measurement of the array voltage and current. They are implemented using microcontrollers, digital signal processors (DSP), field programmable gate arrays (FPGA) or application specific integrated circuits (ASIC) depending on factors such as cost per unit and number of units required. Techniques using microprocessors are favored because of their flexibility and compatibility with different PV arrays. Some of the existing MPPTs are discussed below along with their advantages and disadvantages as compared to the proposed approach.

\subsubsection{Perturb and observe algorithm}

This algorithm is known as 'perturb and observe $(\mathrm{P} \& \mathrm{O})$ ' as they continuously change the solar array operating point and observe the change in array output power. If the change results in an increase in power, it is repeated in the same direction. If the result is a decrease in power, the change is reversed. A pictorial representation is show in 
Figure 1.7 [21]. The operating point is disturbed at every tracking cycle and upon reaching the MPOP, the operating voltage oscillates around it.

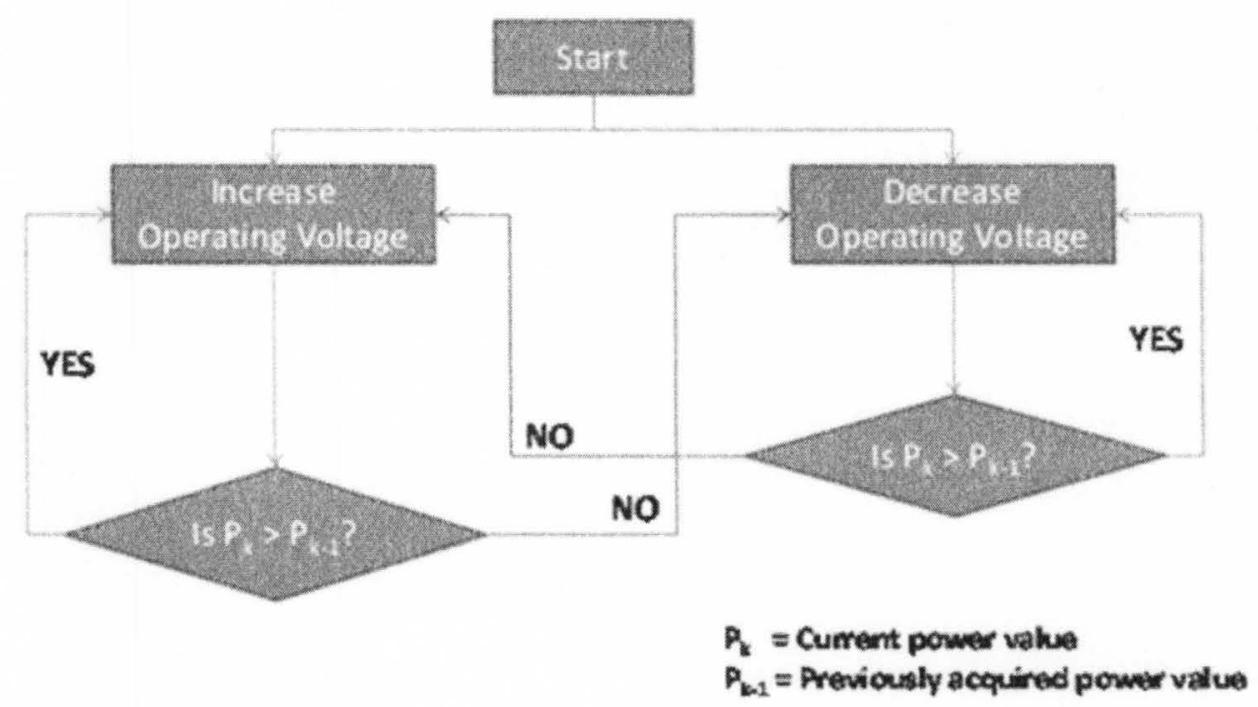

Figure 1.7: Perturb and observe algorithm

This phenomenon is shown in Figure 1.8 and leads to loss of power which is considerably high in case of varying atmospheric conditions.

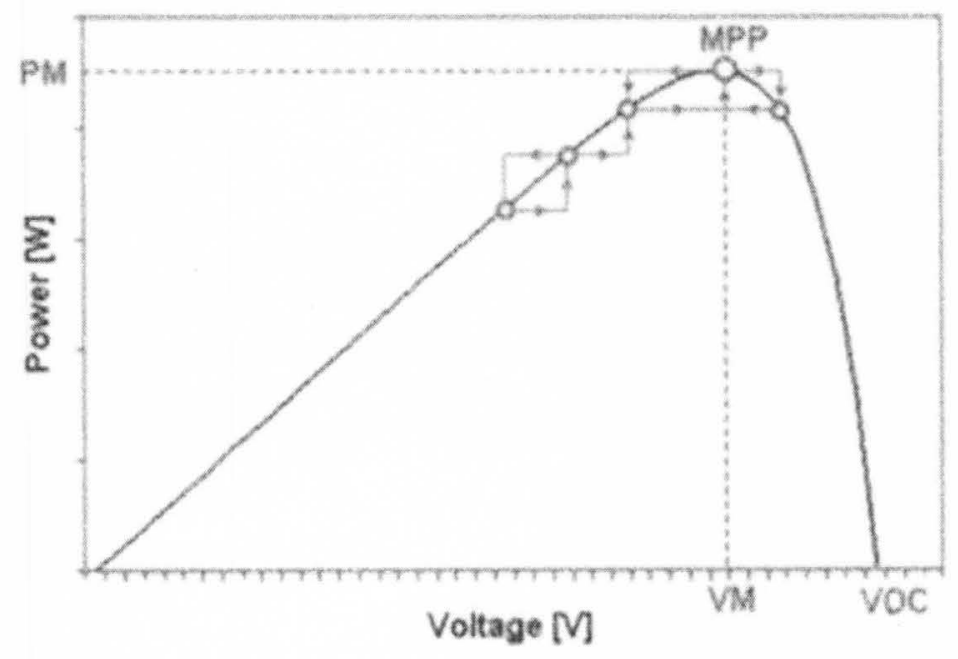

Figure 1.8: Oscillations at maximum power point 
The authors in [1] discuss this algorithm along with its advantages and disadvantages. This method is commonly used due to its ease of implementation. Drawbacks of this system include oscillations at MPP and inability to track MPOP under rapidly varying irradiance levels.

\subsubsection{Sliding-mode observer}

Sliding-mode observer is discussed in [7] to develop a grid-connected PV system and consists of solar array, input capacitor, single-phase inverter, filter inductor and grid voltage. The full-bridge inverter converts DC input voltage from solar array to an $\mathrm{AC}$ voltage by means of appropriate switching signals. Figure 1.9 [7] shows the arrangement.

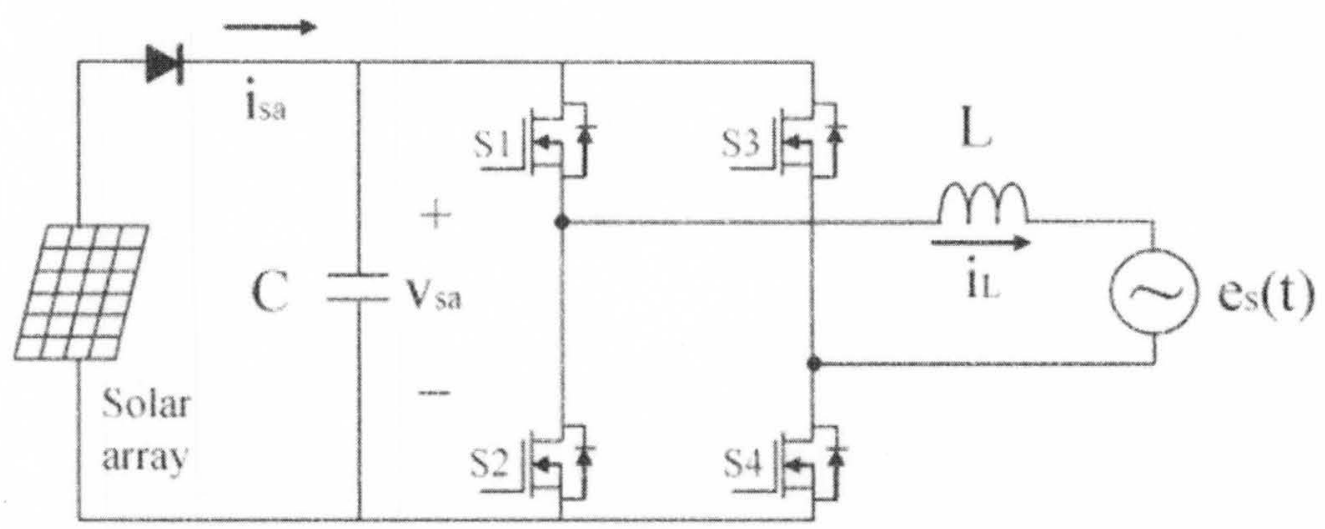

Figure 1.9: Sliding-Mode observer system

This system eliminates the need to measure solar array current to get information on array power and conductance. It takes advantage of the close relation of solar array current with inductor current and estimates the array current using state observer. The performance of state observer degrades year by year as the value of capacitor and inductor varies from their nominal value as years pass by. As a solution to this, sliding- 
mode observer was designed to estimate the array current information. The estimated current information is fed to the trajectory generator and it generates the MPOP voltage trajectory. Sliding-mode observer is generally robust against disturbances in parameter values and atmospheric conditions; but there exists a trade-off between the robustness and stability.

\subsubsection{Voltage feedback method}

The authors in [1] discuss the voltage feedback method to track maximum power from solar arrays. This method uses array terminal voltage as the control variable. In this method, a fixed predefined voltage is considered to be the MPOP and the controller matches array voltage to this voltage. The approximation is done by assuming a constant value for the cell temperature and solar insolation. This method works well in situations of constant solar insolation and temperature and where major variations are in the load; for example in satellite systems. In situations of varying atmospheric conditions, this approach leads to significant loss of power as the method assumes that any variation in the cell temperature and solar insolation are insignificant. In applications where the atmospheric conditions change rapidly, this method is not preferred.

An improvement to the voltage feedback method is open circuit voltage method. This technique uses the fact that a solar cell operates close to the MPOP when the cell voltage is equal to $76 \%$ of the open circuit voltage. This factor is fixed for a given PV generator regardless of the atmospheric conditions. The converter used is a DC-to-DC converter and open circuit voltage of the solar array is measured by interrupting the normal operation. This involves shutting down the converter for about $0.5 \mathrm{~ms}$ every 
second which results in loss of power. Reference voltage is generated by calculating $76 \%$ of the measured open circuit voltage and this value is given as input to the controller. The controller compares the solar panel voltage with the reference voltage and generates error signal which is used as an input to pulse width modulated control of the DC-to-DC converter. The drawback associated with this method is that since it uses a fixed factor of $76 \%$ to generate the reference voltage, the peak power point cannot be truly tracked in all situations.

\subsubsection{Fuzzy logic controller}

The basis of this method is the perturb and observe rule. To implement the rule, fuzzy sets are defined and used. The mechanism is realized by means of a look up table (LUT), which is referred to as control table.

\begin{tabular}{|c|c|c|c|c|c|c|c|c|c|c|c|}
\hline & \multicolumn{11}{|c|}{$\Delta e_{n}(n)$} \\
\hline & -5 & .4 & -3 & -2 & -1 & 0 & 1 & 2 & 3 & 4 & 5 \\
\hline .5 & 11 & 11 & 11 & 11 & 8 & 5 & 5 & 5 & 5 & 5 & 5 \\
\hline-4 & 8 & 8 & 8 & 8 & 6 & 5 & 5 & 5 & 5 & 5 & 5 \\
\hline 3 & 5 & 6 & 6 & 5 & 5 & 5 & 5 & 5 & 5 & 5 & 5 \\
\hline 2 & 0 & 0 & 0 & 0 & 2 & 5 & 5 & 5 & 5 & 5 & 5 \\
\hline-1 & -2 & -2 & -2 & -2 & 0 & 2 & 4 & 5 & 5 & 5 & 5 \\
\hline 0 & -5 & 5 & -5 & -5 & -2 & 0 & 2 & 5 & 5 & 5 & 5 \\
\hline 1 & -5 & -5 & .5 & -5 & -4 & -2 & 0 & 2 & 2 & 2 & 2 \\
\hline 2 & -5 & 5 & -5 & -5 & .5 & -5 & 2 & 0 & 0 & 0 & 0 \\
\hline 3 & .7 & -8 & -8 & -7 & 6 & 5 & -3 & -2 & 2 & 2 & -2 \\
\hline 4 & -10 & -9 & -9 & -10 & -7 & -5 & 4 & 3 & -3 & -3 & -3 \\
\hline 5 & 11 & -11 & 11 & .11 & -8 & .5 & -5 & -5 & -5 & 5 & -5 \\
\hline
\end{tabular}

Figure 1.10: LUT of fuzzy logic controller 
Figure 1.10 shows an LUT associated with MPPT discussed in [9]. The LUT contains the value of control variable for a given pair of inputs. These values are constructed by using fuzzy inference techniques. The table is often built by hand based on extensive experiments. In case of a self-organizing fuzzy logic controller, the controller can recursively adjust its associated fuzzy rule in accordance with the desired response. This helps in reducing error and also the time required to track MPOP. This type of system is preferred in cases where cost involved is not the major concern.

Some of these systems have been modeled in real life while others have been modeled using simulation software. The system discussed in this thesis employs incremental conductance algorithm to generate the MPOP voltage trajectory, backstepping tracking controller to generate the control signals, a controlled rectifier to transfer the power from solar panel to grid and is modeled using MATLAB/Simulink.

\subsection{Thesis organization}

In Chapter 2, the dynamic model of a solar cell used in this thesis is reviewed along with the equations for array current and power. This section is followed by the solar power generating system along with the equations that describe the dynamic behavior of the circuit. These equations along with the equations for current and power generated by the solar array are used to develop a backstepping controller to track the desired array voltage. The section also details the incremental conductance algorithm along with the backstepping controller and corresponding closed loop error system. Stability of the system is also discussed here. In Chapter 3, numerical simulation results 
and conclusions are included. Finally, future work is depicted in Chapter 4 which is followed by references. 


\section{CHAPTER 2}

\section{PV ENERGY SYSTEM}

PV energy system discussed here is a grid-connected system and consists of a string of solar panels that generates the required power level, converter to transfer power to the grid and grid voltage that acts as an $\mathrm{AC}$ source. Each of these are connected as shown in Figure 2.4 to form the complete system. The following sections discuss each of these blocks in detail.

\subsection{Array dynamics}

A PV cell can be considered as a constant current source. Figure 2.1 [8] shows the current-voltage characteristics of a solar cell. It can be seen that the current remains constant up to a limiting voltage after which it collapses. The amplitude of power generated depends on the solar insolation and array temperature. The power is higher in case of better insolation and lower array temperature. For this reason, mechanical systems are used to track the direction and path of sun throughout the day so that the cells receive maximum insolation. In addition to that, cooling mechanisms are included in PV array systems to keep the array temperature low. 


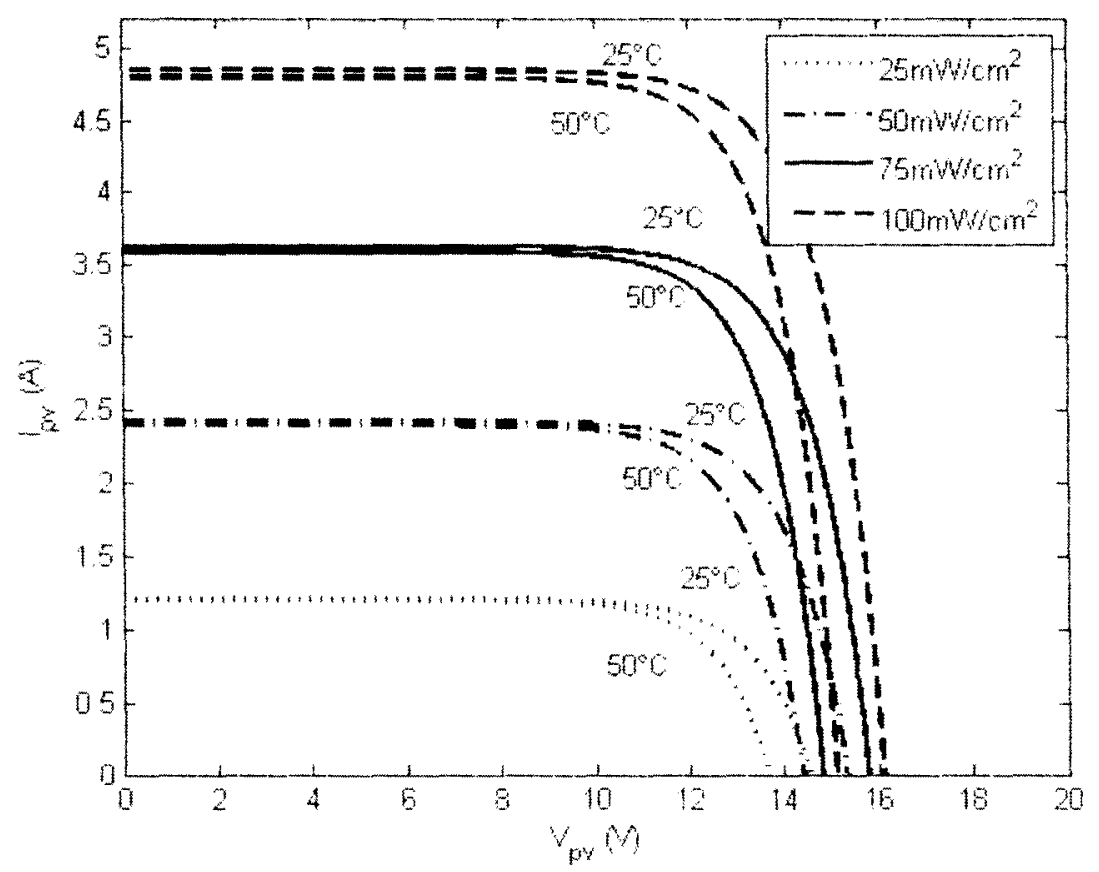

Figure 2.1: Current - voltage characteristics of solar array

Figure $2.2[8]$ shows the power-voltage characteristics of solar arrays. Since power is the product of current and voltage, its dependence on solar insolation and array temperature follows that of the current. From Figures 2.1 and 2.2 it is apparent that the solar arrays have a highly non-linear nature. Factors such as cell parameters and atmospheric conditions play an important role in the non-linearity of solar arrays. It is evident from Figure 2.2 that at each instant, there exist an array operating voltage at which the power transferred to load is maximized and this operating voltage is the MPOP. As the characteristic curve varies with changing solar radiation and cell temperature, the MPOP also changes. Continuous adjustment of the array voltage needs to be made to track the maximum power from arrays. 


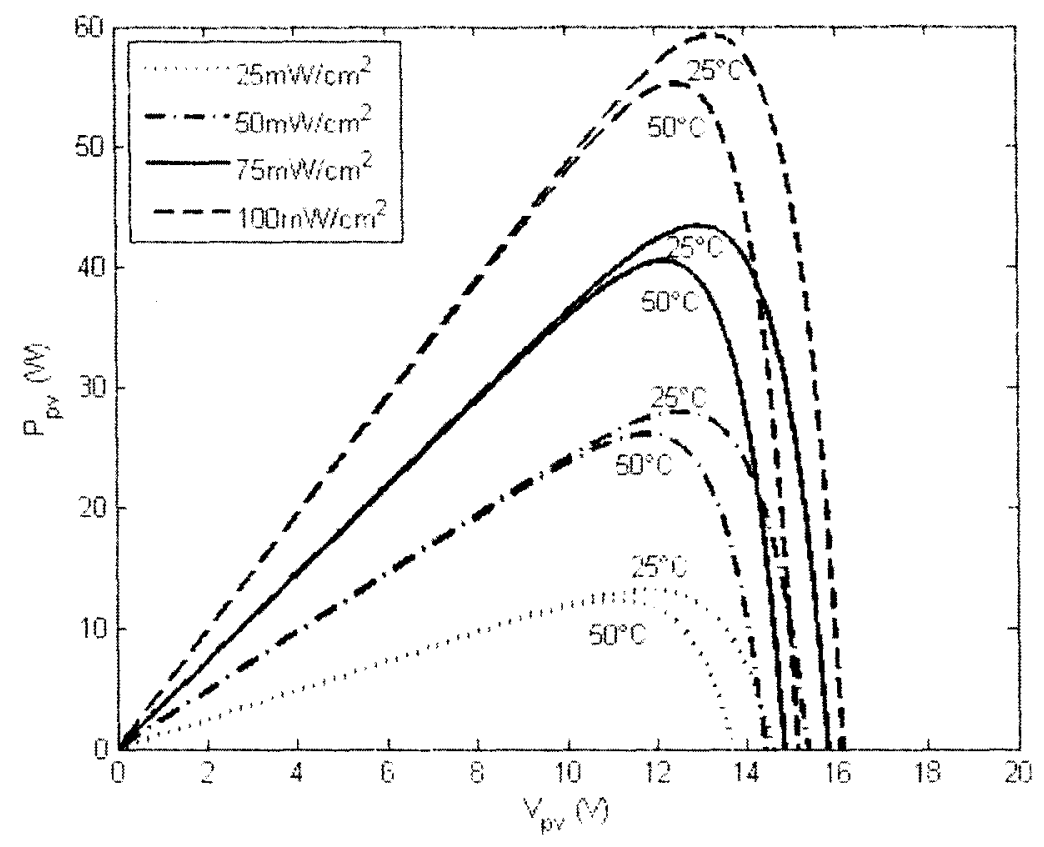

Figure 2.2: Power-voltage characteristics of solar array

\subsection{Array parameters}

This section defines the equations used to model the solar array which is part of the converter system that is defined in the next chapter. Solar cells can be modeled by the equivalent circuit shown in Figure 2.3 [7]. The current generated by an array is given by the equation [8]:

$$
i_{p v}=n_{p} I_{p h}-n_{p} I_{r s}\left(e^{\frac{q v_{p v}}{n_{s} A K T}}-1\right)
$$

where $i_{p v}(t) \in \mathbb{R}$ is the PV array output current; $v_{p v}(t) \in \mathbb{R}$ is the PV array output voltage; $n_{s}$ is the number of cells connected in series; $n_{p}$ is the number of cells connected in parallel; $q$ is the charge of an electron; $K$ is the Boltzmann's constant; $A$ is 
the $p-n$ junction ideality factor; and $\mathrm{T}$ is the cell temperature in Kelvin $(\mathrm{K}) ; I_{r s} \in \mathbb{R}$ is the reverse saturation current and $I_{p h} \in \mathbb{R}$ is the photocurrent.

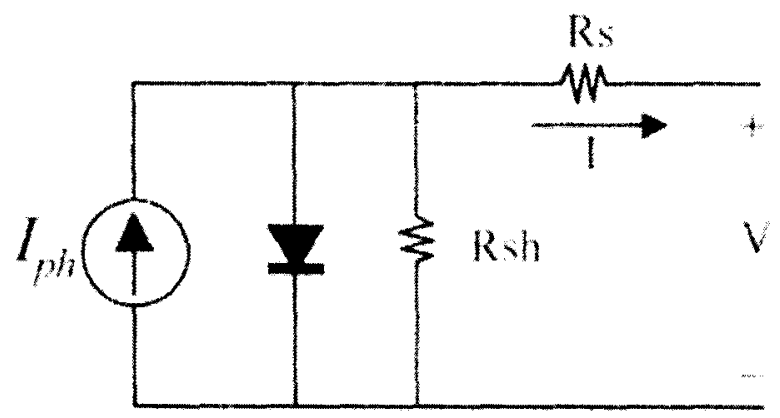

Figure 2.3: Equivalent circuit of a solar cell

$R_{s}$ is the series resistance and $R_{s h}$ is the shunt resistance. The reverse saturation current and photocurrent can be expressed as:

$$
\begin{aligned}
& I_{r s}=I_{o r}\left(\frac{T}{T_{r}}\right)^{3} e^{\frac{q E g o}{K T}\left(\frac{1}{T_{r}}-\frac{1}{T}\right)} \\
& I_{p h}=\left(I_{s c}+K_{l}\left(T-T_{r}\right)\right) \frac{\lambda}{100}
\end{aligned}
$$

where $I_{o r}$ is the reverse saturation current at reference temperature, $T_{r} ; E_{g o}$ is the band gap energy of semiconductor; $I_{s c}$ is the short-circuit cell current at the reference temperature and radiation; $K_{l}$ is the short-circuit current temperature coefficient; and $\lambda$ is the solar radiation in $m W / \mathrm{cm}^{2}$. The PV array output power, $P_{p v}(t)$, is the product of the array voltage and current and can be calculated as:

$$
P_{p v}=i_{p v} v_{p v}=n_{p} I_{p h} v_{p v}-n_{p} I_{r s} v_{p v}\left(e^{\frac{q v_{p v}}{n_{s} A K T}}-1\right)
$$

The controller maximizes this power by controlling the array voltage $v_{p v}$. 


\subsection{Converter}

The converter used in this thesis is a single-phase full wave controlled rectifier. The full wave rectifier converts a DC input voltage into an $\mathrm{AC}$ sinusoidal voltage, indirectly controlling the voltage of $\mathrm{PV}$ array, $v_{p v}(t)$ and thus the array power generation. It acts as an interface between the array and utility connection. Ideal full wave rectifier has four basic components, namely power semiconductor switches, input capacitor, resistor-inductor (RL) load and a PWM controller. The topology is shown in Figure 2.4. The diode prevents the power flow from utility grid back into the solar panel. The converter converts DC-to-AC by proper switching of the controlled switches.

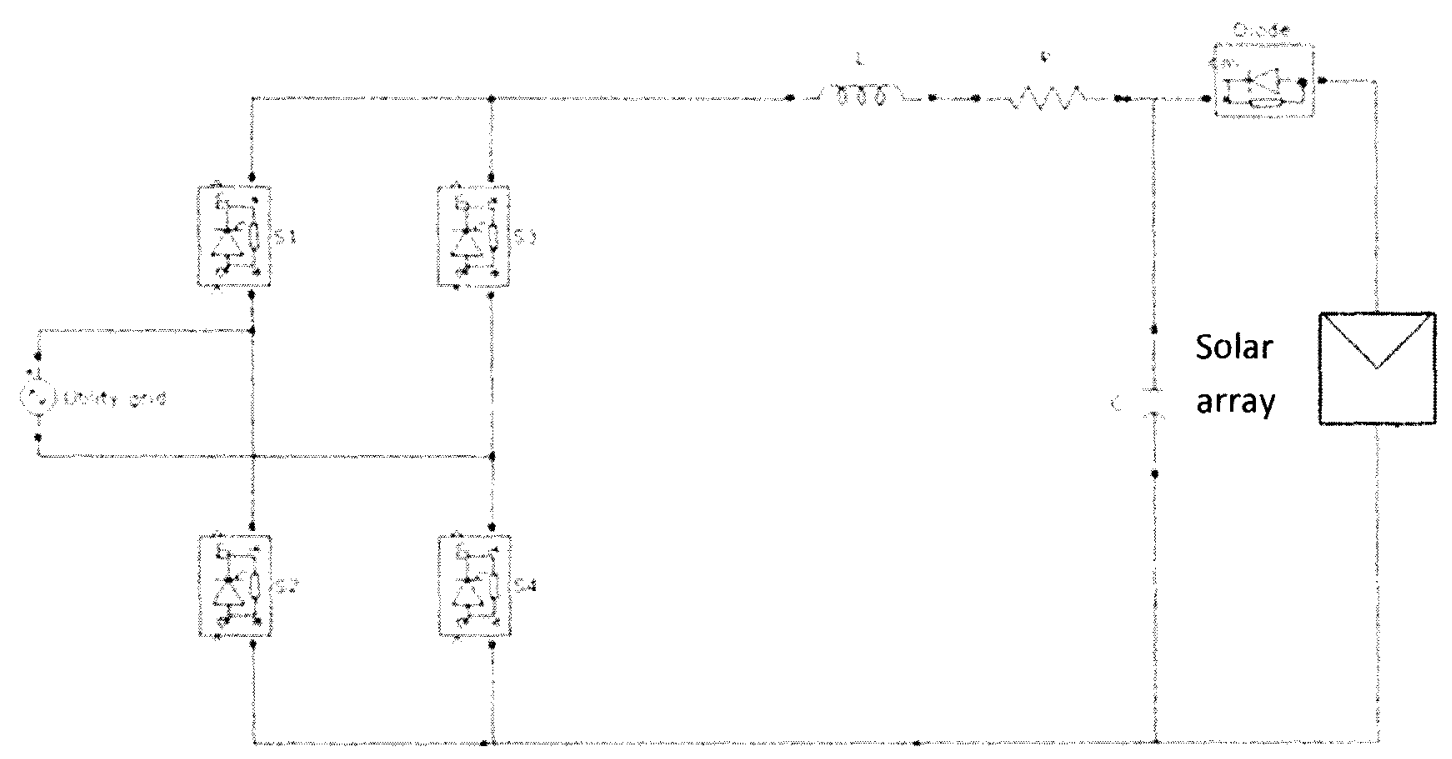

Figure 2.4: Grid-connected PV system 


\subsubsection{Controlled rectifier operation}

The switches used in place of S1, S2, S3 and S4 are controlled switches such as silicon controlled rectifier (SCR) or insulated gate bipolar transistor (IGBT). The output voltage is controlled by adjusting the delay angle of each switch. The switches S1 and S4 become forward-biased during the positive half-cycle of $\mathrm{AC}$ utility voltage but will not conduct until the gate signals are applied. The circuit during the positive half-cycle of AC voltage is shown in Figure 2.5.

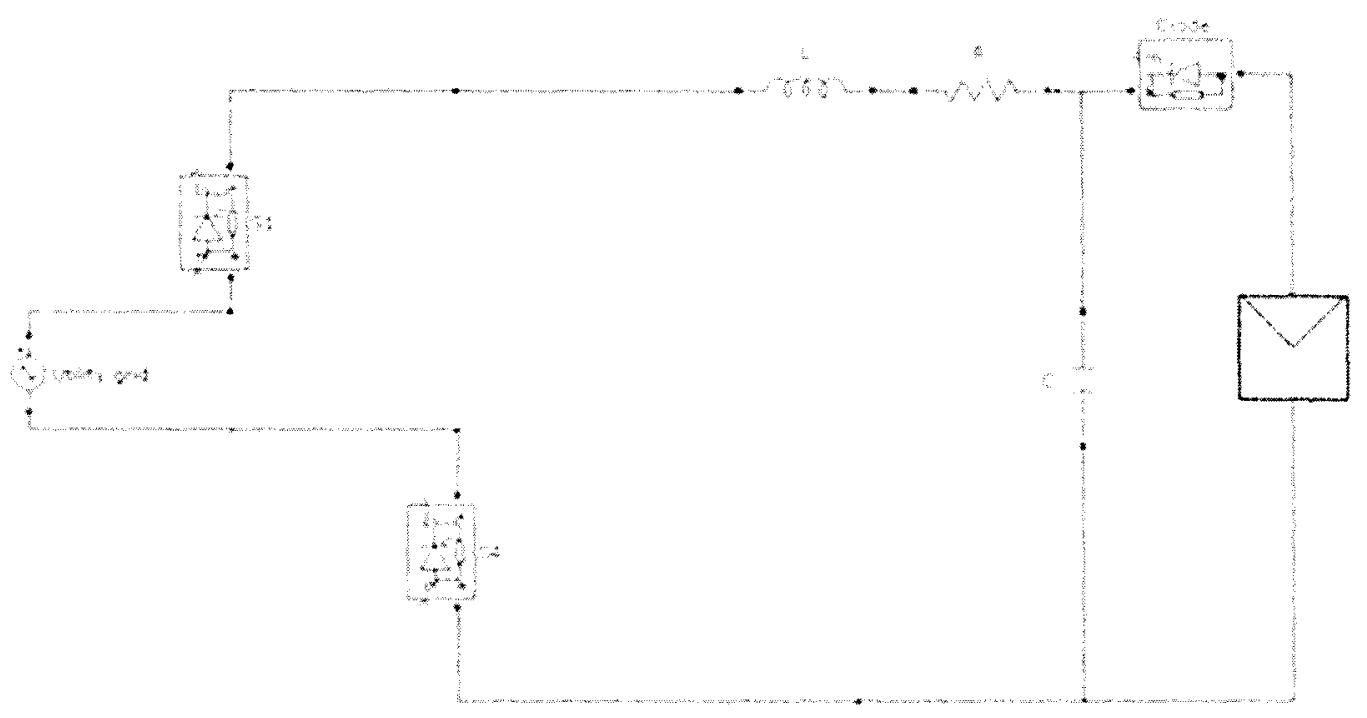

Figure 2.5: Positive half-cycle operation

Similarly, S2 and S3 will become forward-biased during the negative half-cycle of AC utility voltage but will not conduct until they receive the gate signals. Figure 2.6 shows the circuit during the negative half-cycle of $\mathrm{AC}$ voltage. 


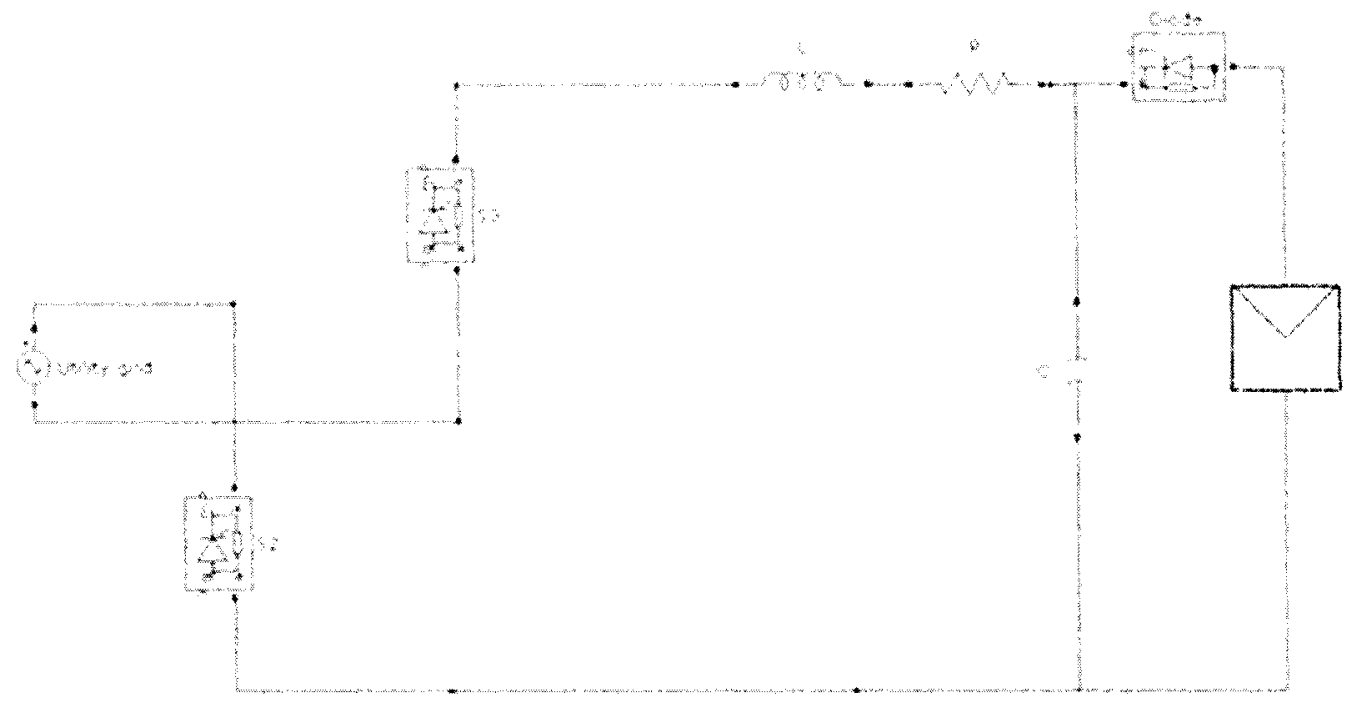

Figure 2.6: Negative half-cycle operation

The delay angle $\alpha$ is the angle interval between forward biasing of the switch and the gate signal application. For a delay angle of $0^{\circ}$, the circuit behaves exactly as an uncontrolled rectifier with an RL-source load. When the circuit behaves as a rectifier, it converts ACto-DC and the power flow is from the $\mathrm{AC}$ voltage source to the load. The output voltage is shown in Figure 2.8 with the AC utility voltage shown in Figure 2.7. The average DC voltage across capacitor is taken as $50 \mathrm{~V}$. 


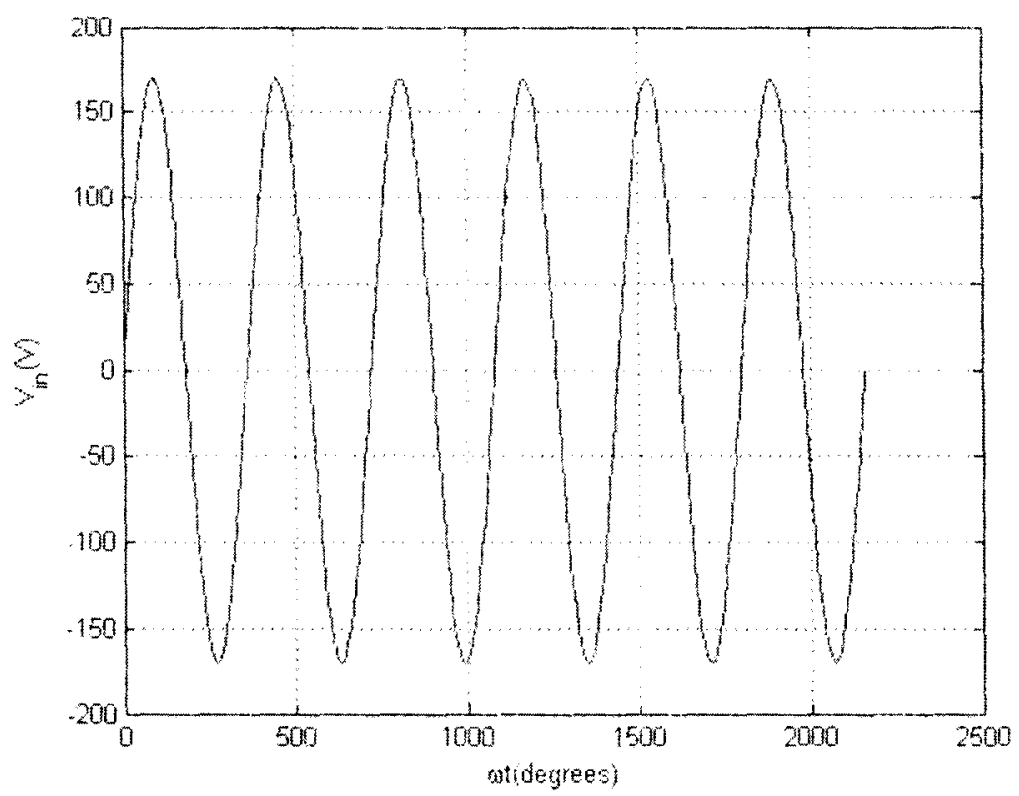

Figure 2.7: Utility voltage

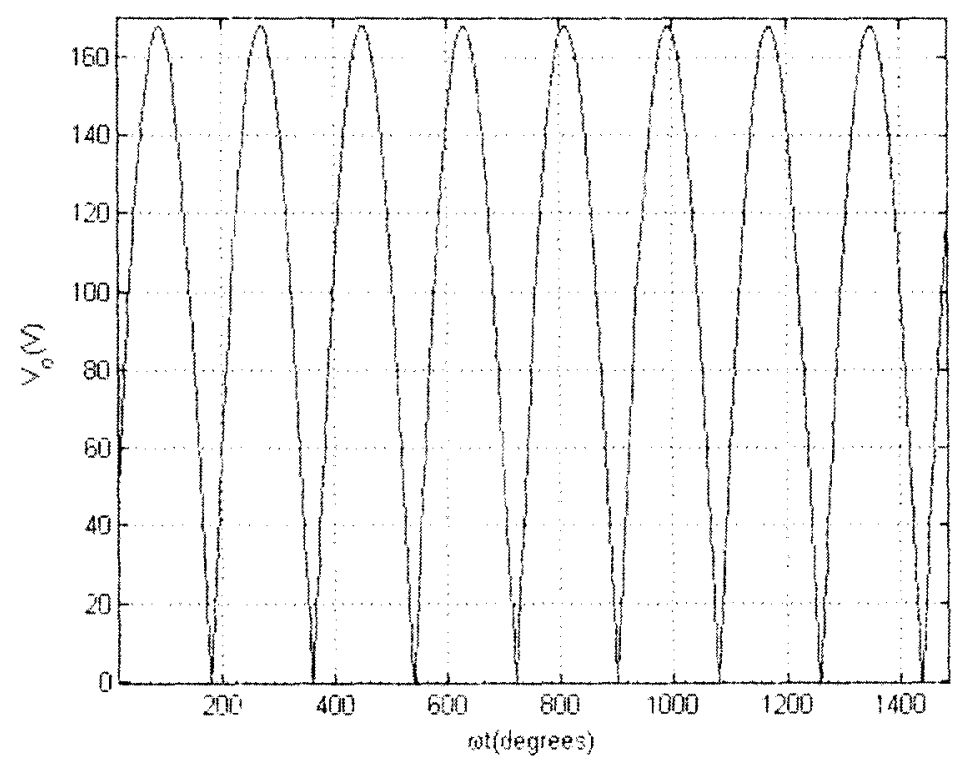

Figure 2.8: Rectifier output voltage

The converter functions as a controlled rectifier when the firing angle for switches is between $0^{\circ}$ and $90^{\circ}$. Output of the converter for a firing angle of $40^{\circ}$ and continuous 
inductor current is shown in Figure 2.9. It is clear from this figure that the switches conduct after a delay of $40^{\circ}$.

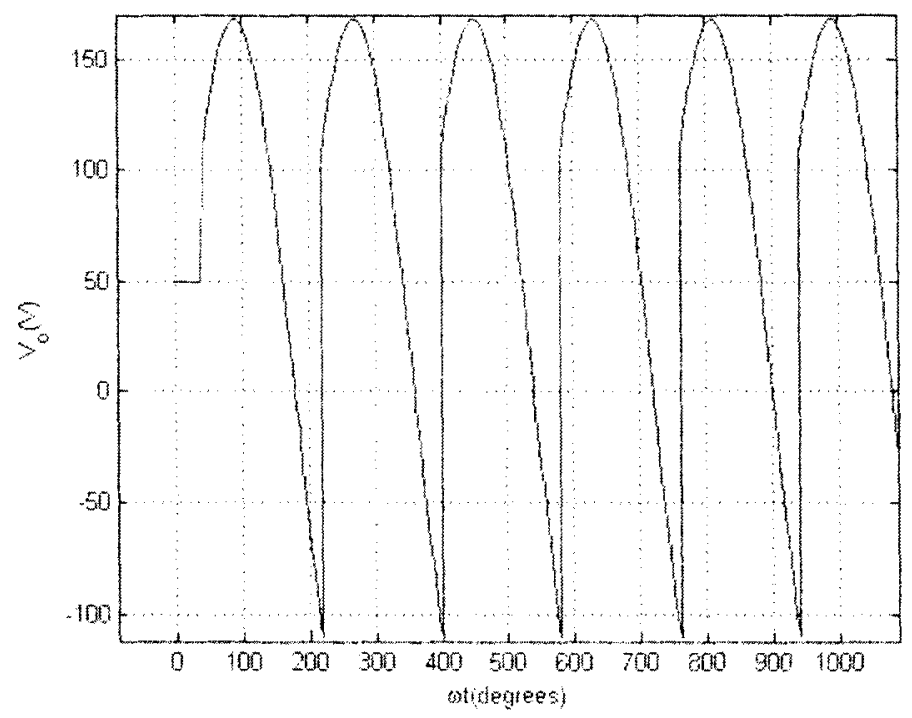

Figure 2.9: Rectifier output voltage with delay angle $40^{\circ}$

When the firing angle is between $90^{\circ}$ and $180^{\circ}$, the converter functions as an inverter. An inverter converts $\mathrm{DC}$-to- $\mathrm{AC}$ and the power flow is from the $\mathrm{DC}$ voltage source to the load. Here, the DC voltage source is the solar array and the load is the utility grid. The output voltage for a firing angle of $140^{\circ}$ is shown in Figure 2.10. In this case, the average $\mathrm{DC}$ voltage across the capacitor is taken as $-110 \mathrm{~V}$. To meet the required objective which is to transfer power from the solar array to the grid, the firing angle needs to be between $90^{\circ}$ and $180^{\circ}$ and the PV array is connected such that the voltage across it is negative. In case the firing angle drops below $90^{\circ}$, the power flows from the grid to the solar array, which is prevented by the diode as it gets reverse biased and disconnects the grid from the array. The inductor $\mathrm{L}$ reduces the $\mathrm{AC}$ current spikes and causes the load current to be continuous. 


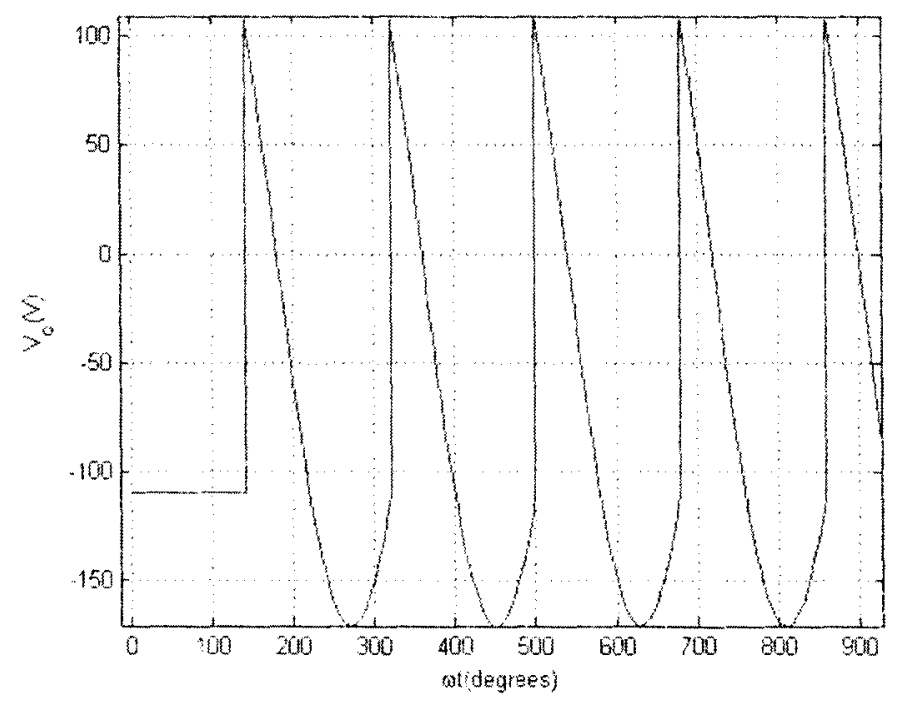

Figure 2.10: Rectifier output voltage with delay angle $140^{\circ}$

\subsubsection{Circuit dynamics}

Dynamic equations for current and voltage is derived using the Kirchhoff's current law (KCL) and Kirchhoff's voltage law (KVL). The conventions used for deriving the equations are defined in Figure 2.11. Using KCL at node 1,

$$
i_{L}=i_{p v}+i_{C}
$$

where $i_{L}(t)$ is the current through inductor, $i_{C}(t)$ is the current through capacitor and $i_{p v}(t)$ is the current supplied by the string of solar panels. Rearranging (2.4) to get the equation for capacitor current:

$$
i_{C}=i_{L}-i_{p v} .
$$


Current through the capacitor can be represented as the product of capacitance and derivative of voltage across the capacitor. Applying this to (2.5), yields the following:

$$
C v_{C}=i_{L}-i_{p v}
$$

where $v_{C}(t)$ is the voltage across capacitor and $\mathrm{C}$ is the value for capacitance. It is clear from Figure 2.11 that $v_{C}=v_{p v}$ when the diode is forward biased. Thus replacing $v_{C}(t)$ with $v_{p v}(t)$ in equation (2.6), yields:

$$
C v_{p v}=i_{L}-i_{p v}
$$

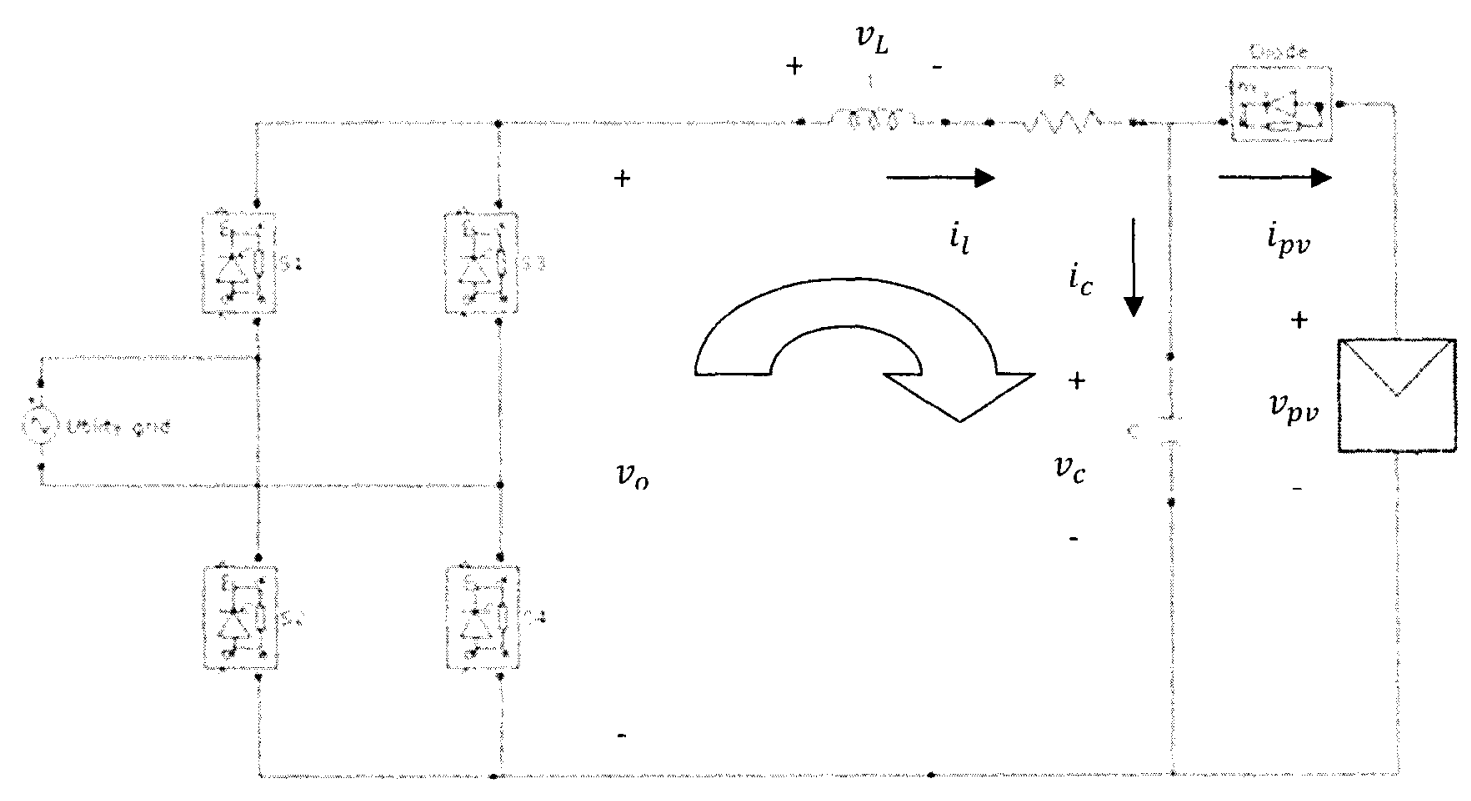

Figure 2.11: Conventions followed

Applying KVL in the loop and assuming the voltage across diode to be zero when it is forward biased,

$$
-v_{o}+v_{L}+v_{R}+v_{p v}=0
$$


where $v_{L}(t)$ and $v_{R}(t)$ are the voltages across the inductor and resistor respectively. Rearranging the equation (2.8) and replacing with $v_{L}$, it yields:

$$
L \dot{i}_{L}=v_{o}-R i_{L}-v_{p v}
$$

Using the state averaging method [25], equations (2.7) and (2.9) can be redefined by the average model as follows:

$$
\begin{aligned}
& L \dot{I}_{L}=V_{o}-R I_{L}-V_{p v} \\
& C \dot{V}_{p v}=I_{L}-I_{p v}
\end{aligned}
$$

where $V_{p v}(t) \in \mathbb{R}$ and $I_{p v}(t) \in \mathbb{R}$ are the average states of the output voltage and current of the string of solar panel; $I_{L}(t) \in \mathbb{R}$ is the average state of the inductor current; $V_{o}(t) \in \mathbb{R}$ is the average state of the AC output voltage of the converter and is defined by the equation:

$$
V_{o}=\frac{2 V_{m}}{\pi} \cos (\alpha)
$$

where $V_{m}$ is the peak voltage of the AC utility grid and $\alpha$ is the firing angle. To facilitate the control design, the following model characteristics are assumed:

Assumption l: $V_{p v}(t), I_{p v}(t)$, and $I_{L}(t)$ are measurable.

Assumption 2: $\mathrm{C}$ and $\mathrm{L}$ are known constants.

Assumption 3: $I_{p v}(t)$ is bounded provided that $V_{p v}(t)$ is bounded. 
Assumption $4: I_{p v}^{\cdot}(t)$ can be upper bounded by a positive constant such that $\left|I_{p v}\right|<\mu$ where $\mu € \mathbb{R}^{+}$.

\subsection{Trajectory generation algorithm}

The algorithm used in this thesis to track MPOP is the incremental conductance algorithm. This algorithm relates the changes in PV array power to the changes in atmospheric conditions and adjusts the array terminal voltage according to its value relative to the MPOP. To adjust the array voltage, the derivative of array power with respect to voltage is considered. The basic idea is that at MPOP, value for this derivative vanishes. This is because at MPOP, the operating point is at the maximum of power curve shown in Figure 2.2. Also we can note from this figure that to the left of the MPOP, the power is increasing with the voltage, denoted by $d P / d V>0$. To the right of MPOP, the power is decreasing with the voltage, which can be represented as $d P / d V<$ 0 . The above statements can be rewritten in simple equations as follows:

$$
\begin{aligned}
& d P / d V=0 \text { at the MPOP } \\
& d P / d V>0 \text { to the left of the MPOP } \\
& d P / d V<0 \text { to the right of the MPOP. }
\end{aligned}
$$

Substituting the array power by the product of array voltage and current, the following equation is obtained

$$
\frac{d P}{d V}=\frac{d(I V)}{d V}=I+V \frac{d I}{d V}
$$


Hence, by measuring the incremental and instantaneous array conductance and by utilizing the above equations, the PV array terminal voltage can be adjusted relative to the MPOP voltage. The algorithm is explained with the flow chart shown in Figure 2.12. $V_{n}$ and $I_{n}$ are the present values of array voltage and current; $V_{b}$ and $I_{b}$ are the respective values stored at the end of preceding cycle; $V_{r}$ is the control reference signal generated and $\Delta V$ is the adjustment made to the reference signal at the end of each cycle.

The algorithm starts by obtaining the present values of array current and voltage. Using the respective values stored at the end of preceding cycle, it calculates the incremental changes approximated as: $d I=I_{n}-I_{b}$ and $d V=V_{n}-V_{b}$. The algorithm then compares $d I / d V$ against $-I / V$ and updates the control reference signal, $V_{r}$ according to the result. The adjustment is made in order to move the array terminal voltage towards the MPOP. If $d I / d V=-I / V$, the operating point is at the MPP and no control action is needed. Therefore adjustment stage will be bypassed and the algorithm will update the stored parameters at the end of cycle as usual. In case if $d V=0$, the change in atmospheric conditions is detected by observing $d I$. If $d I=0$, the control action is bypassed and in other cases, the reference signal adjustment will depend on whether $d l$ is positive or negative, as shown in flow chart.

The algorithm is programmed in Simulink using a user-defined function. At MPOP, the condition $d P=0$ seldom occurred because of the approximation made in the calculation of $d I$ and $d V$. This condition can be detected in simulation by allowing a small marginal error in the comparison. That is, instead of comparing $d P$ to $0, d P$ is 
compared to $\pm E$ where $\mathrm{E}$ is the error. The value of $\mathrm{E}$ depends on the required sensitivity of the tracking system. 


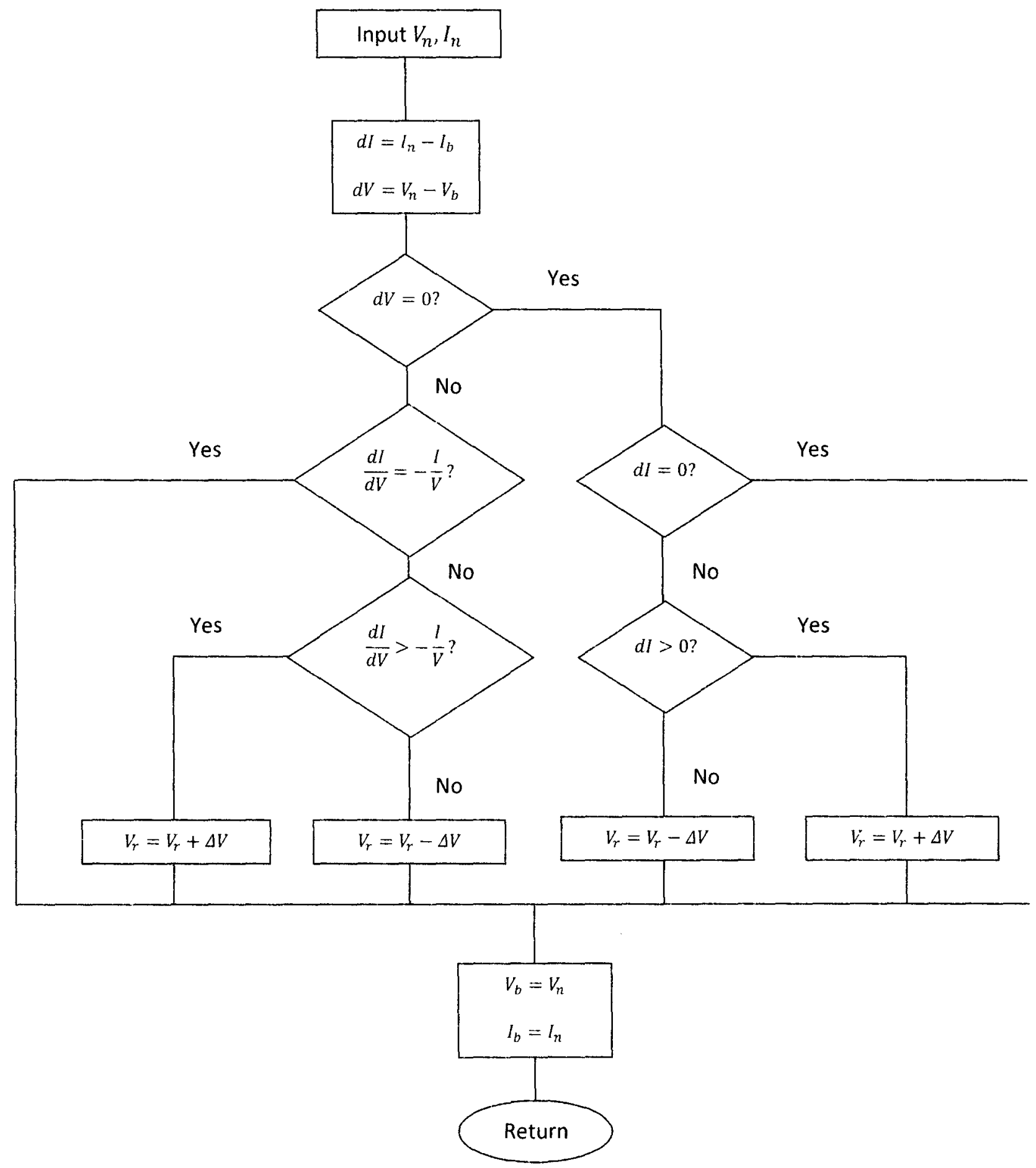

Figure 2.12: Incremental conductance algorithm 


\subsection{Controller Design}

The control objective is to maximize the power extracted from solar array, $P_{p v}(t)$ by tracking a developed array voltage, $V_{d}(t) \in \mathbb{R}$. The controller has to ensure that the array voltage $V_{p v}(t)$ tends to $V_{d}(t)$ as $t \rightarrow \infty$. This is achieved by controlling the firing angle, $\alpha(t)$ at which the switches start conducting once they are forward biased. The desired array voltage is developed using the incremental conductance algorithm described in the previous section. As $V_{d}(t) \rightarrow V^{*}$, where $V^{*}$ is the unknown optimal array voltage, $P_{p v}(t) \rightarrow P_{\max }$ which is the maximum power. The developed array voltage, $V_{d}(t)$ is designed to be sufficiently differentiable, that is $V_{d}(t), \dot{V}_{d}(t), \ddot{V}_{d}(t) \in \mathcal{L}_{\infty}$. To ensure that they are bounded, a filter-based form of the incremental conductance algorithm is used. During each iteration, the discrete guess, $V_{d}[n]$, is passed through a set of second order stable and proper low pass filters to generate continuous bounded signals for $V_{d}(t), \dot{V}_{d}(t), \ddot{V}_{d}(t)$. The following filters were used during simulation.

$$
\begin{aligned}
& V_{d}(t)=\frac{\zeta_{2}}{s^{2}+\zeta_{1} s+\zeta_{2}} V_{d}[n] \\
& \dot{V}_{d}(t)=\frac{\zeta_{2} s}{s^{2}+\zeta_{1} s+\zeta_{2}} V_{d}[n] \\
& \ddot{V}_{d}(t)=\frac{\zeta_{2} s^{2}}{s^{2}+\zeta_{1} s+\zeta_{2}} V_{d}[n]
\end{aligned}
$$

where $s \in \mathbb{C}$ is the Laplace variable, $\zeta_{2}, \zeta_{1} \in \mathbb{R}^{+}$are filter constants and $n \in \mathbb{Z}^{+}$.

\subsubsection{Error system development}


Closed loop error signal, $e(t)$ is defined as the difference between the desired and actual array voltage and is given by the equation:

$$
e=v_{d}-v_{p v}
$$

Error signal associated with current is represented by $\eta(t)$ and is defined as the difference between the desired inductor current, $I_{d}(t)$ which is a subsequently defined auxiliary control input and the actual inductor current, $I_{L}(t)$.

$$
\eta=i_{d}-i_{L}
$$

The desired inductor current is designed as follows:

$$
i_{d}=C \dot{v}_{d}+i_{p v}+k_{1} e
$$

where $k_{1} \in \mathbb{R}^{+}$is a control gain. From the definition of tracking errors in (2.20) and (2.21) and the circuit dynamics in (2.10) and (2.11), an open loop system is developed as follows:

$$
\begin{aligned}
& C \dot{e}=C \dot{V_{d}}+I_{p v}-I_{d}+\eta \\
& L \dot{\eta}=V_{p v}+R I_{L}-V_{o}+L \dot{I_{D}} .
\end{aligned}
$$

The output voltage of the converter, $V_{o}(t)$ is designed as follows:

$V_{o}=V_{p v}+R I_{L}+C L \ddot{V}_{d}+k_{1} L \dot{V}_{d}+k_{1} \frac{L}{C} I_{p v}-k_{1} \frac{L}{C} I_{L}+k_{2} \eta+e+k_{3} \operatorname{sgn}(\eta)$

where $k_{1}, k_{2}, k_{3} \in \mathbb{R}^{+}$are control gains, and $\operatorname{sgn}($.$) is the standard signum function.$ Using (2.12), the equation for calculating the firing angle is developed and is given by: 


$$
\alpha=\cos ^{-1}\left(\frac{V_{o} \pi}{2 V_{m}}\right)
$$

Substituting (2.22) and (2.25) into the open loop error dynamics of (2.23) and (2.24), closed loop error system is developed as follows:

$$
\begin{aligned}
& C \dot{e}=\eta-k_{1} e \\
& L \dot{\eta}=-k_{2} \eta-e-k_{3} \operatorname{sgn}(\eta)+L I_{p v} .
\end{aligned}
$$

\subsection{Stability analysis}

This thesis makes use of Lyapunov stability analysis to analyze the stability of the closed loop system. According to the theorem, if all solutions of a dynamic system that start out near an equilibrium point stay near the point forever, then the point is Lyapunov stable. Stability analysis is done to make sure that the error signals $e(t)$ and $\eta(t)$ tend to zero as $t \rightarrow \infty$. This indirectly ensures that the array voltage, $V_{p v}(t)$ tracks the desired array voltage, $V_{d}(t)$ generated using the extremum-seeking algorithm. The system is stable if it can be proved that:

$$
e(t), \eta(t) \rightarrow 0 \text { as } t \rightarrow \infty
$$

\subsubsection{Proof}

A non-negative scalar function, $V(t) \in \mathbb{R}$ is defined by the equation:

$$
V=\frac{1}{2} C e^{2}+L \eta^{2}
$$

Taking the time derivative of this equation, the following expression is obtained: 


$$
\dot{V}=C e \dot{e}+L \eta \dot{\eta}
$$

Substituting with equations (2.27) and (2.28) and cancelling similar but opposite terms, equation (2.31) yields the following:

$$
\dot{V}=-k_{1} e^{2}-k_{2} \eta^{2}+\eta L I_{p v}^{\cdot}-k_{3} \eta \operatorname{sgn}(\eta) \text {. }
$$

From (2.32), $\dot{V}(t)$ can be upper bounded as follows:

$$
\dot{V} \leq-k_{1}|e|^{2}-k_{2}|\eta|^{2}-\left(k_{3}-L\left|I_{p v}\right|\right)|\eta| \text {. }
$$

If the control gain $k_{3}$ is designed such that $k_{3}>L\left|\mathrm{I}_{\mathrm{pv}}\right|$, then $\dot{V}(t)$ can be upper bounded. This follows that $e(t), \eta(t) \in \mathcal{L}_{\infty}$. Since $e(t) \in \mathcal{L}_{\infty}$, it follows from (2.20) that $V_{p v}(t), V_{d}(t) \in \mathcal{L}_{\infty}$. Based on these statements and using the Assumption 3, it can be proven that $I_{p v}(t) \in \mathcal{L}_{\infty}$. In (2.22) all terms towards the right side of the equation are bounded. This makes the term in the left side bounded, that is $I_{d}(t) \in \mathcal{L}_{\infty}$. Utilizing (2.21) and the fact that $I_{d}(t), \eta(t) \in \mathcal{L}_{\infty}$, it is clear that $I_{L}(t) \in \mathcal{L}_{\infty}$. From the definition of the converter output voltage, it follows that $V_{o}(t) \in \mathcal{L}_{\infty}$. Using (2.26), it is clear that $\alpha \in \mathcal{L}_{\infty}$. From the boundedness statements and using (2.10) and (2.11), it can be concluded that the dynamic model terms are bounded, that is, $\dot{I}_{L}(t), \dot{V_{p v}}(t) \in \mathcal{L}_{\infty}$. Using the above boundedness statement and the time derivative of (2.20), it can be shown that $\dot{e}(t) \in \mathcal{L}_{\infty}$. The time derivative of (2.22) along with the boundedness statement and Assumption 4 can be used to show that $\dot{I}_{d}(t) \in \mathcal{L}_{\infty}$. From the time derivative of $(2.21)$, it can be concluded that $\dot{\eta}(t) \in \mathcal{L}_{\infty}$. By employing a corollary to Barbalat's lemma [26], it is clear 
that $e(t), \eta(t) \rightarrow 0$ as $t \rightarrow \infty$. From this, the final conclusion can be made that the algorithm forces the designed array voltage $V_{d}(t)$ to maximize the output power of panel. 


\section{CHAPTER 3}

\section{RESULTS AND CONCLUSIONS}

To verify the novel control scheme, simulations were performed using MATLAB/Simulink. The AC system is the utility grid and is represented by the equation:

$$
V=\sqrt{2} * 120 * \sin (377 t)
$$

Simulation was done for 50 seconds with a fixed step size of 0.000125 . The values used for the constants associated with solar array are given below:

\begin{tabular}{|c|c|}
\hline Parameter & Value \\
\hline$n_{p}$ & 6 \\
\hline$n_{s}$ & 250 \\
\hline$q$ & $1.6 e-19 \mathrm{C}$ \\
\hline$A$ & 1.6 \\
\hline$K$ & $1.3805 e-23 m^{2} k g s^{-2} K^{-1}$ \\
\hline$I_{o r}$ & $2.0793 e-6 \mathrm{~A}$ \\
\hline$T_{r}$ & $301.18 \mathrm{~K}$ \\
\hline$E_{g o}$ & $1.1 \mathrm{eV}$ \\
\hline$I_{s c}$ & $4.8 \mathrm{~A}$ \\
\hline$K_{l}$ & $2.06 e-3 / C^{\circ}$ \\
\hline
\end{tabular}


The values for the constants in controller design are given below:

\begin{tabular}{|c|c|}
\hline Parameter & Value \\
\hline$\zeta_{2}$ & 9 \\
\hline$\zeta_{1}$ & 6 \\
\hline$k_{1}$ & 20 \\
\hline$k_{2}$ & 30 \\
\hline$k_{3}$ & 40 \\
\hline $\mathrm{E}$ & 0.005 \\
\hline
\end{tabular}

The values for the components used in circuit are given below:

\begin{tabular}{|c|c|}
\hline Component & Value \\
\hline $\mathrm{L}$ & $0.48 \mathrm{H}$ \\
\hline $\mathrm{C}$ & $0.25 \mathrm{~F}$ \\
\hline $\mathrm{R}$ & $1 \Omega$ \\
\hline
\end{tabular}

\subsection{Simulation results}

Figures 3.1 and 3.2 show the $\mathrm{i}-\mathrm{v}$ and $\mathrm{p}-\mathrm{v}$ characteristics of the solar array used in this thesis. These figures validate the solar array model described in Section 2.1 and was simulated with varying atmospheric conditions as shown in the legend boxes. 


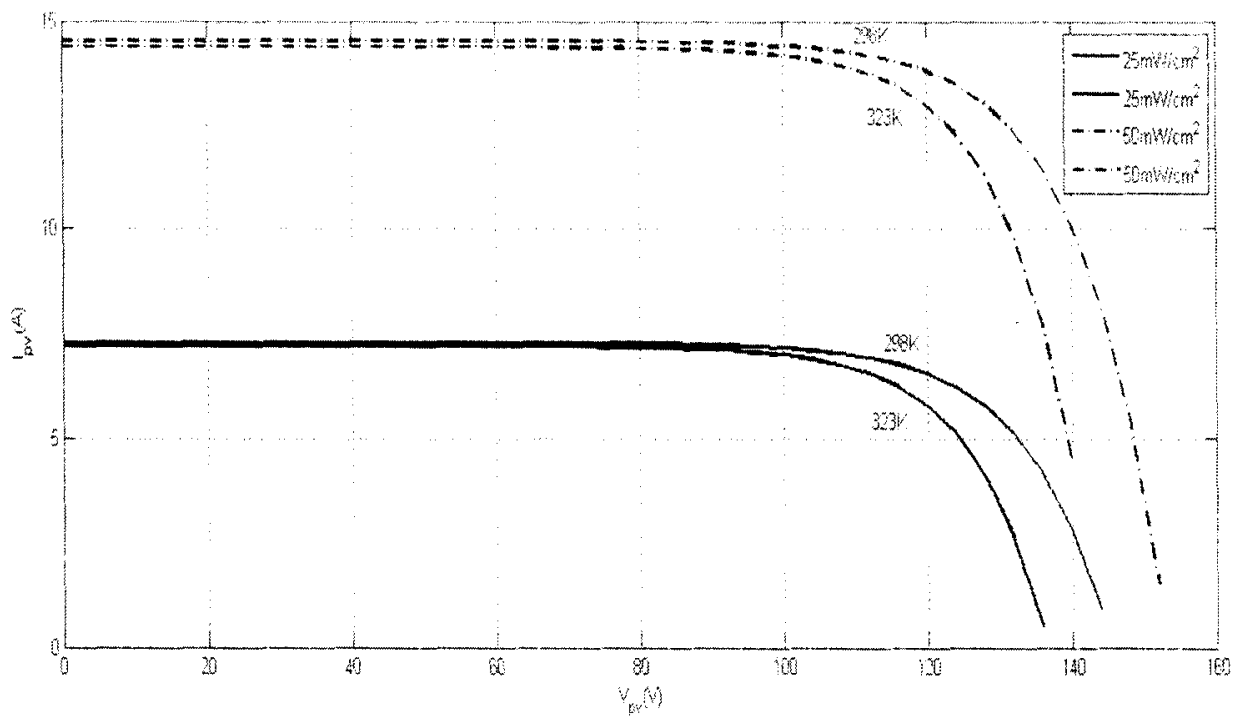

Figure 3.1: i-v characteristics

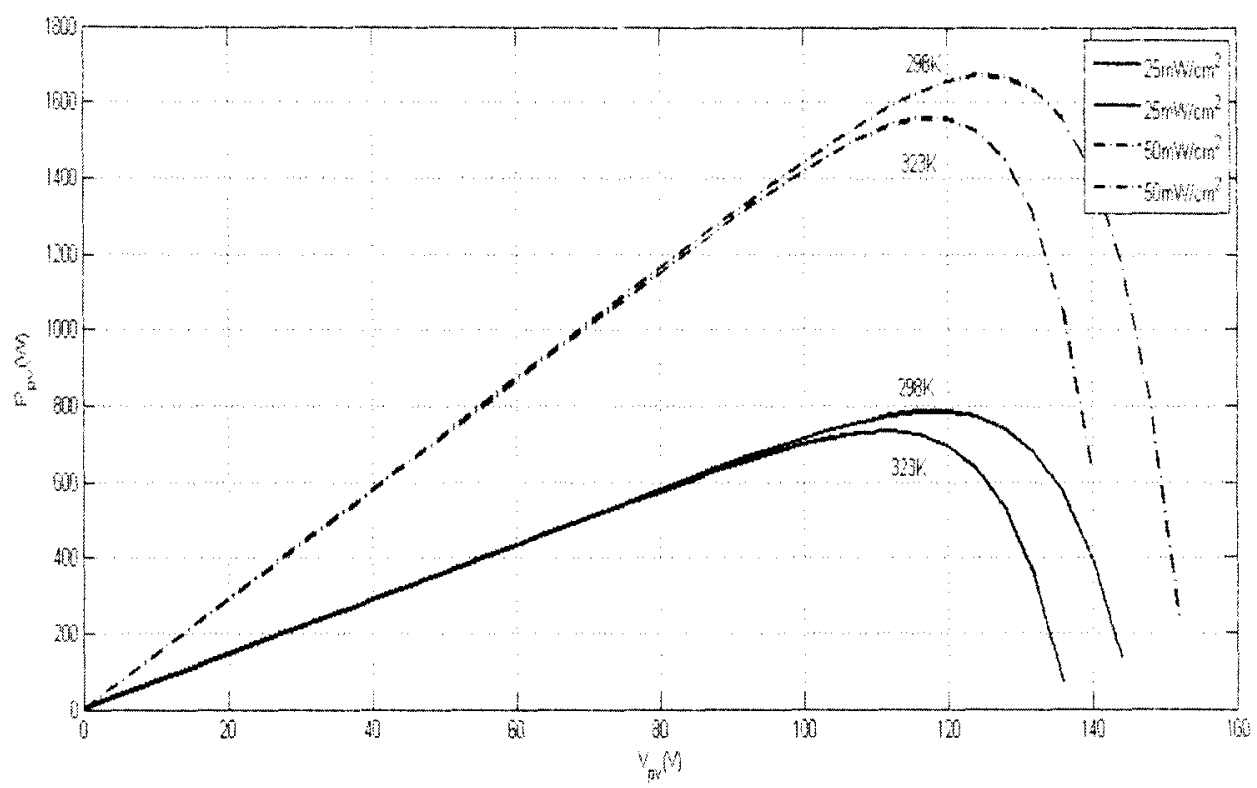

Figure 3.2: $\mathrm{p}-\mathrm{v}$ characteristics

It is important to note that the controller works in presence of varying cell temperature and solar radiation. These variations are shown in Figures 3.3 and 3.4. 


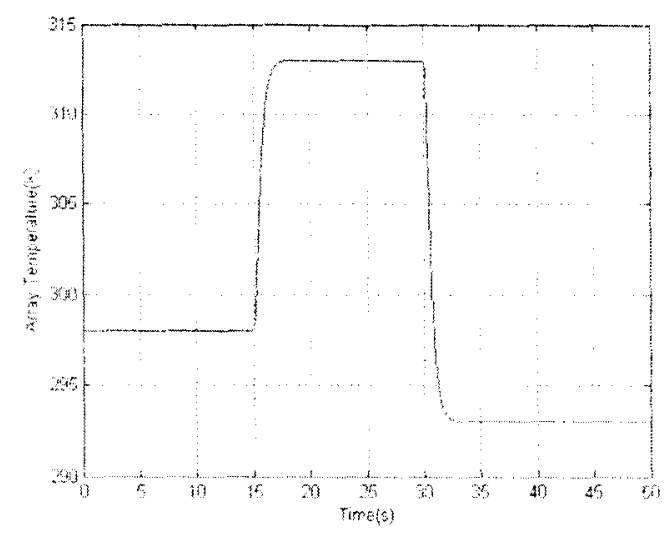

Figure 3.3: Cell temperature

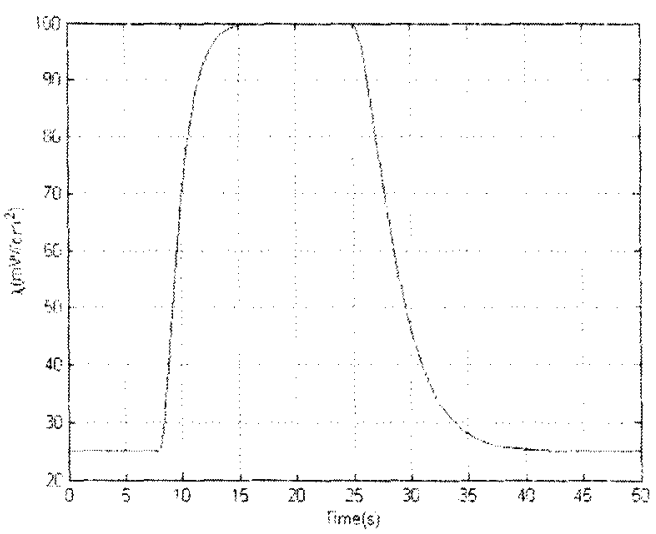

Figure 3.4 Solar radiation

For an array with the above characteristics and atmospheric conditions, the desired trajectory generated by the incremental conductance algorithm is shown in Figure 3.5.

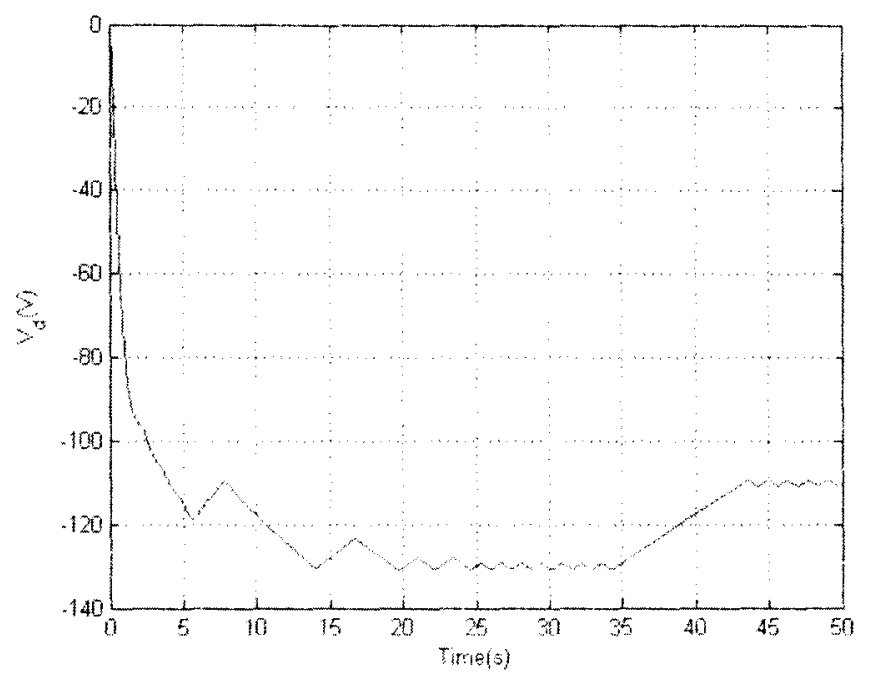

Figure 3.5: Desired voltage trajectory $V_{d}$

It can be seen that the generated trajectory is negative. This makes the array voltage to be negative which in turn makes the converter to function as an inverter. The function of the 
controller is to make the array voltage track the generated trajectory. It is clear from Figure 3.6 that the array voltage follows the desired trajectory with minimum error.

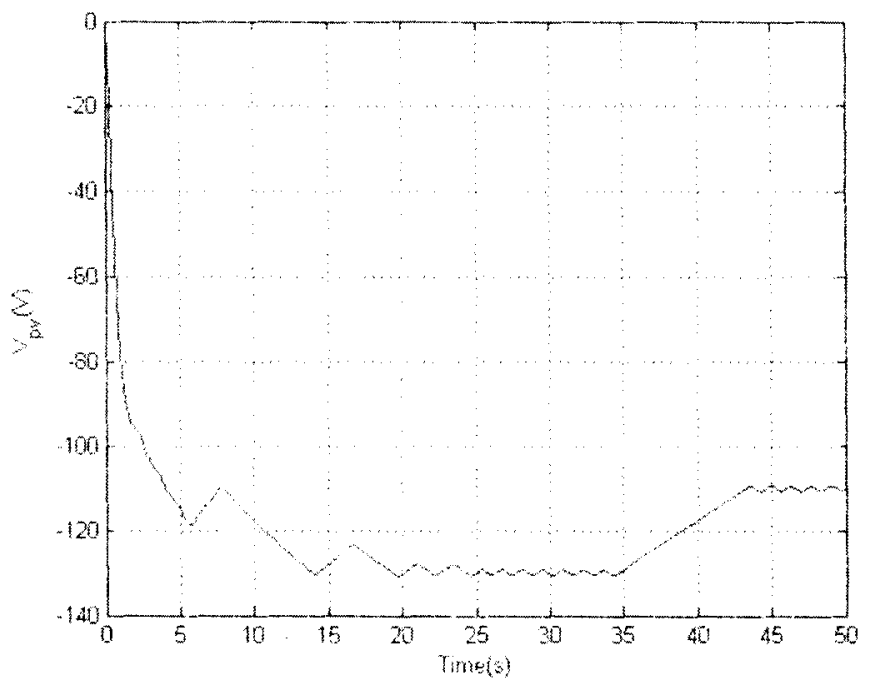

Figure 3.6: Array voltage

The error signal $e(t)$ as defined by the equation (2.20) is approximately zero at all times and is shown in Figure 3.7.

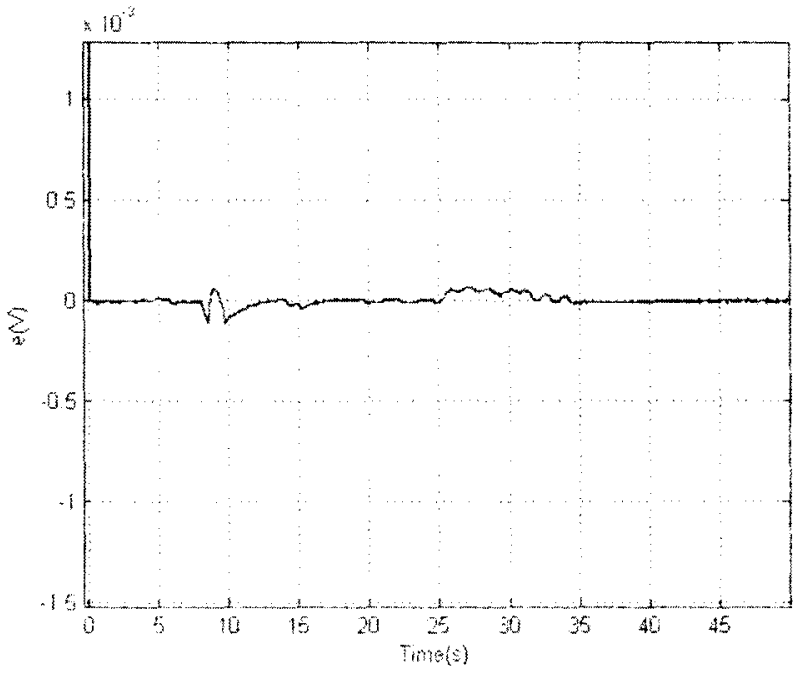

Figure 3.7: Voltage error signal 
The designed array current is shown in Figure 3.8. The obtained array current which is shown in Figure 3.9 follows the designed array current as expected. This is supported by Figure 3.10 which shows the error signal associated with array current. It is clear from this figure that the error is close to zero.

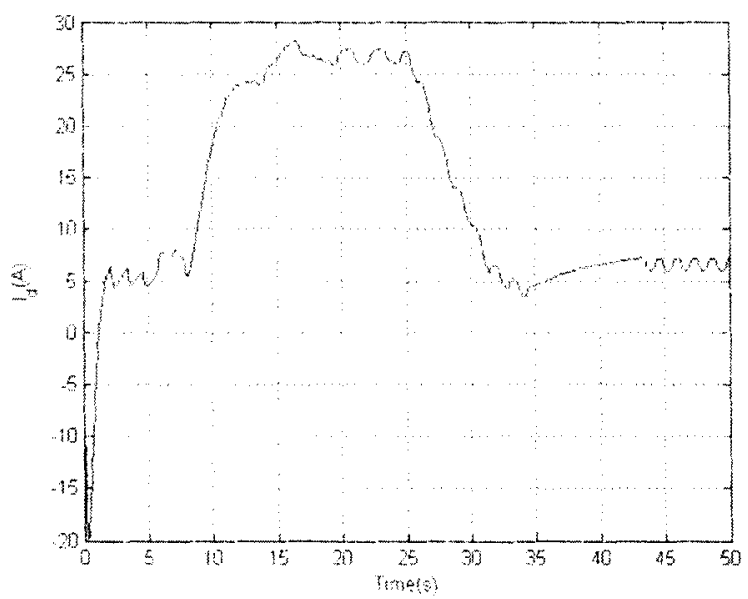

Figure 3.8 Desired array current

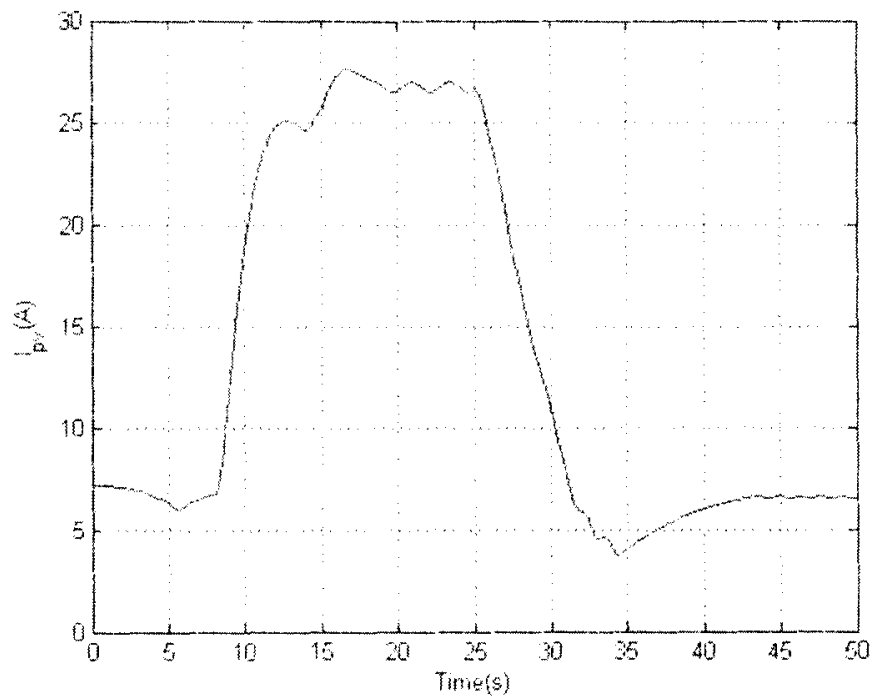

Figure 3.9: Obtained array current 


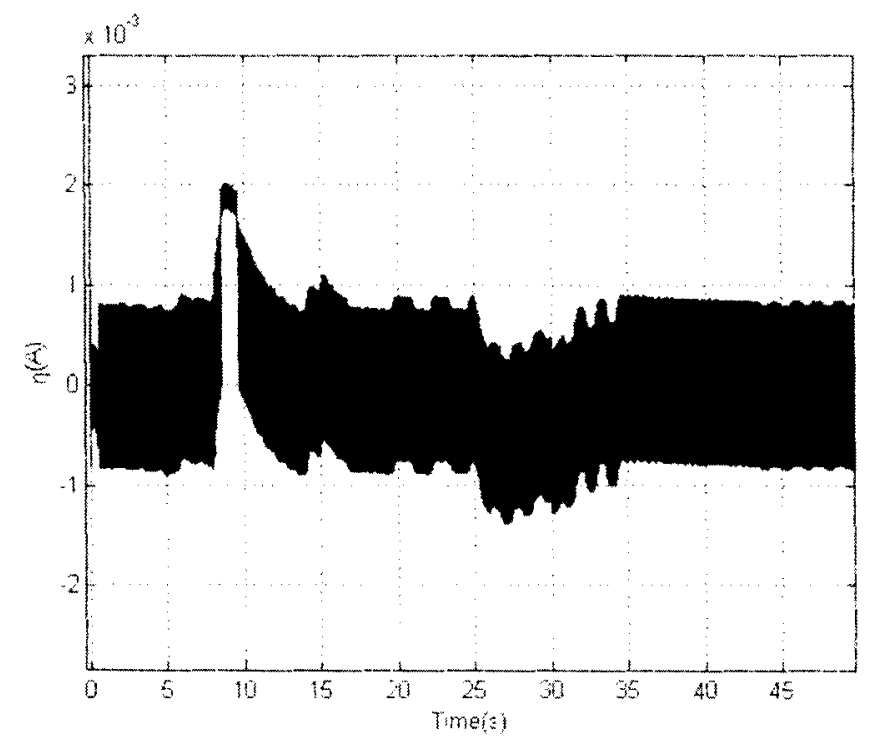

Figure 3.10: Current error signal

The power supplied by solar array is shown in Figure 3.11. It can be seen that the power is negative and according to the conventions followed, it means that the power is being supplied.

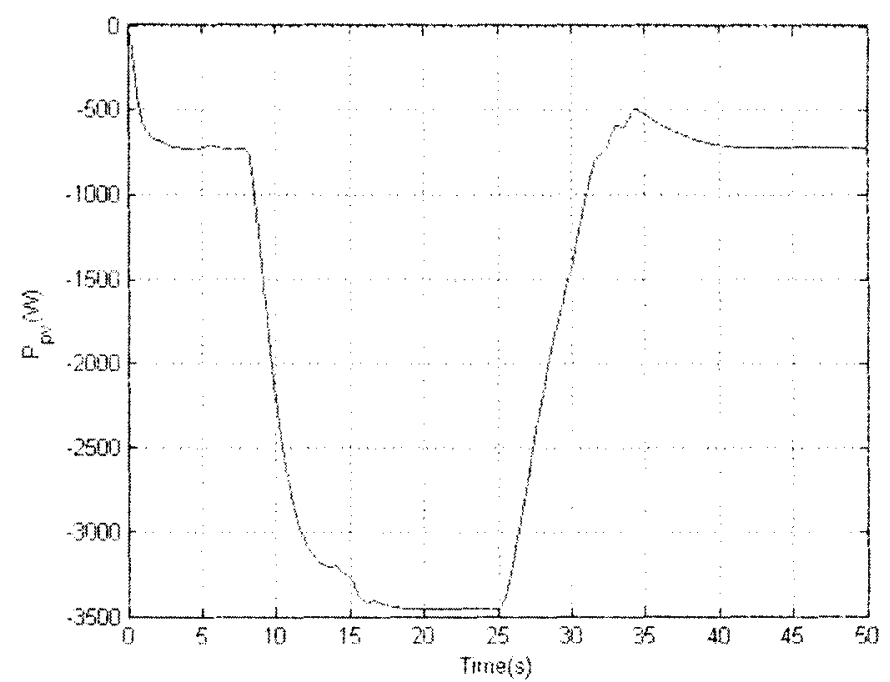

Figure 3.11: Power supplied by solar array 
Part of the power supplied by array is lost across the resistor, and this power loss is shown in Figure 3.12. The resistor was included to account for line losses and this loss would be minimized in an actual system.

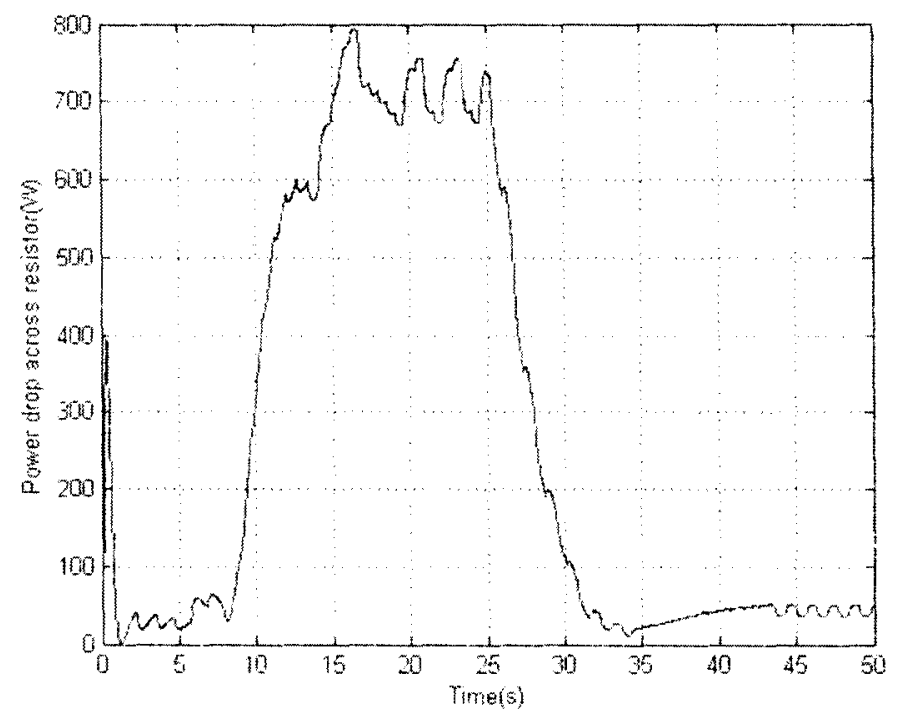

Figure 3.12: Power loss across resistor

The remaining power is supplied to the utility grid and is shown in Figure 3.13. It can be seen that the power drop across resistor and the power supplied to utility is positive; which means that these powers are being absorbed. 


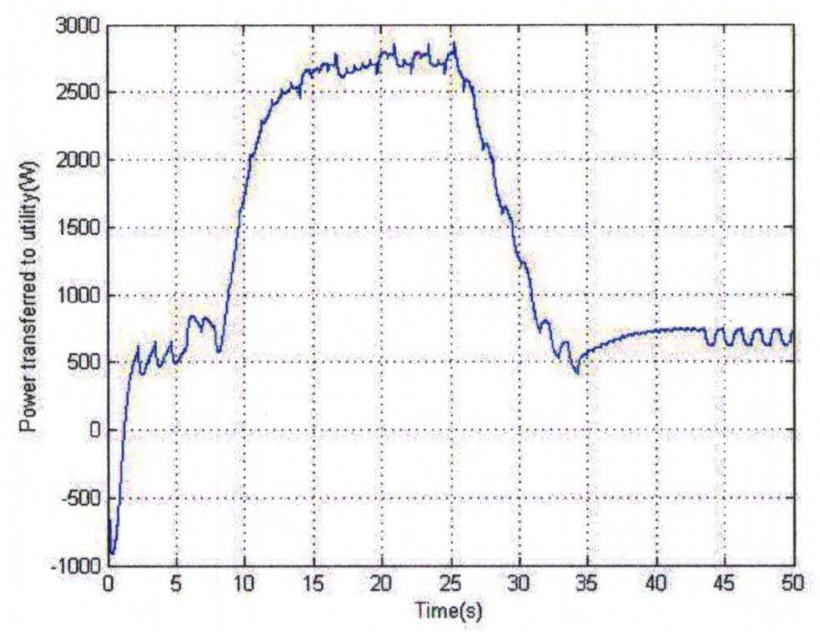

Figure 3.13: AC output power

The power supplied by solar array was compared with the theoretical maximum power that was generated using the max function in MATLAB. This was done to test the functionality of the proposed system. Comparison graph is shown in Figure 3.14 and it can be seen that the array power closely follows the theoretical power.

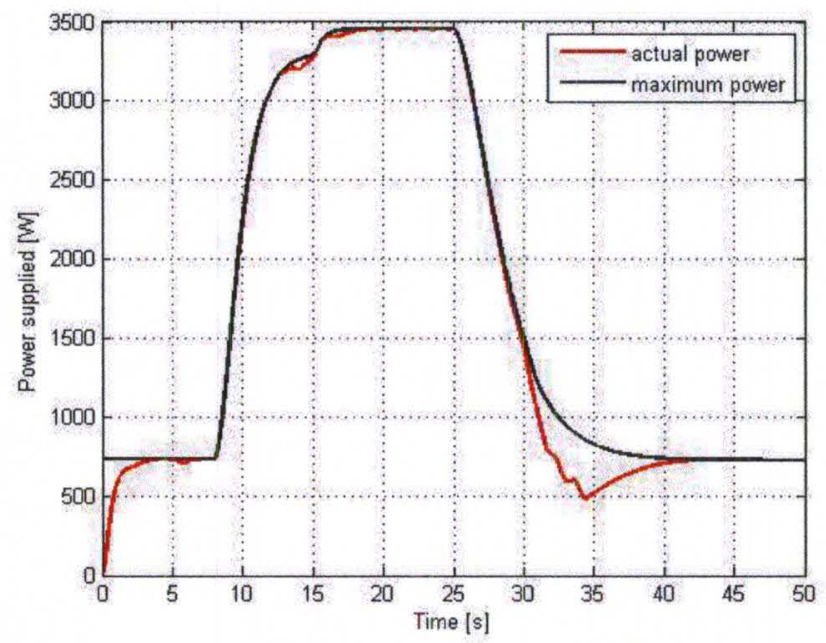

Figure 3.14: Comparison graph 
The average output voltage generated by the system is shown in Figure 3.15 with a magnified image in Figure 3.16.

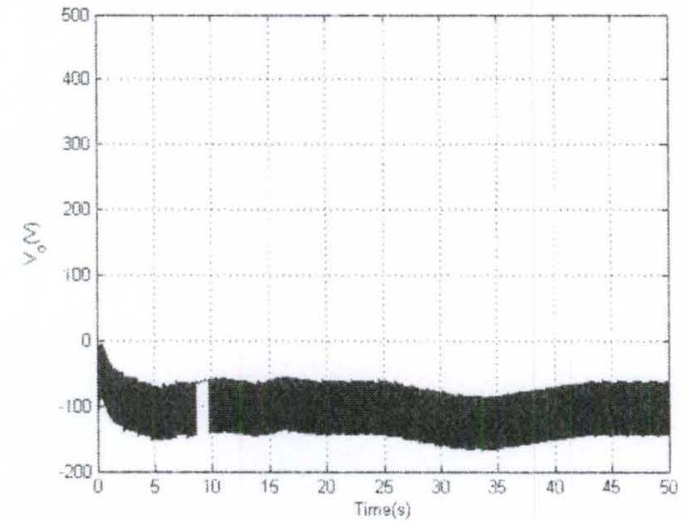

Figure 3.15: Average output voltage

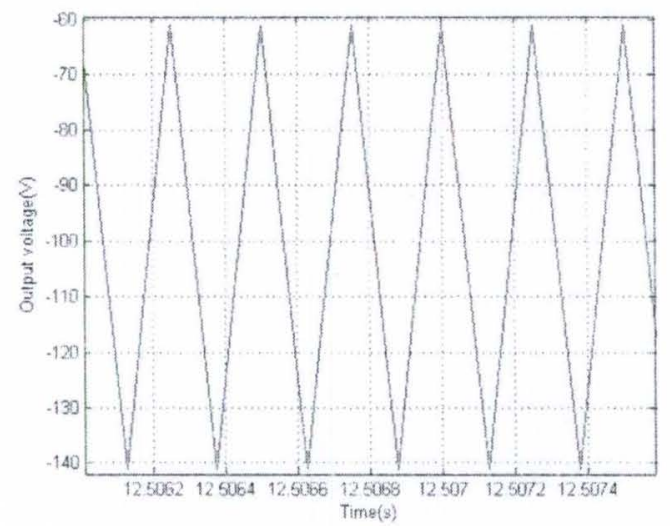

Figure 3.16: Magnified output voltage

Calculated firing angle for the switches is shown in Figure 3.17 with a magnified image in Figure 3.18.

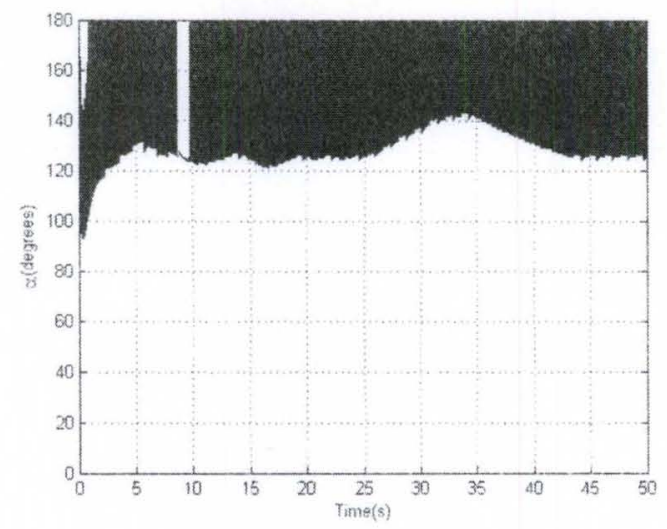

Figure 3.17: Rectifier firing angle $\alpha(t)$

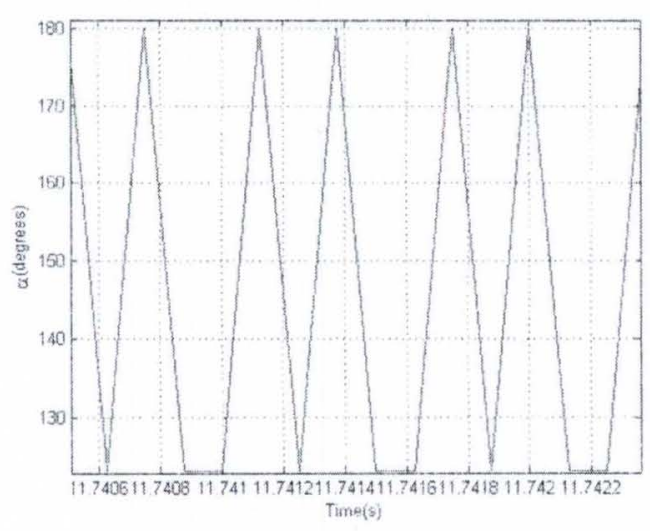

Figure 3.18: Magnified firing angle $\alpha(t)$ 
It is clear from this figure that the firing angle is between $90^{\circ}$ and $180^{\circ}$. This ensures that the converter functions as an inverter and transfers power from the solar array to the grid as expected.

\subsection{Conclusions}

Energy from sun is a promising solution to the world's energy requirements and solar cells can be used to harvest this energy. They convert solar energy to electricity which can be used to supplement the utility grid. The four block approach discussed in this thesis using controlled rectifier, backstepping controller, incremental conductance algorithm and a string of solar arrays is a novel approach towards designing a MPPT. The agreement between the simulation and expected results shows that the proposed system accurately predicts and tracks the MPOP in varying atmospheric conditions. In addition, from Figure 3.14 it is clear that the power supplied by solar array is close to the theoretical maximum value and is large enough for practical applications. The results also re-enforced that the system is not ideal and there are losses in the system that affect the efficiency of the process. 


\section{CHAPTER 4}

\section{FUTURE SCOPE}

This thesis discussed a new approach to track maximum power from solar array and the functionality was demonstrated with simulation studies. An extension of this work could be to implement the system in hardware and test the functionality in real atmospheric conditions. It includes connecting the system to utility grid which in turn requires the output current to be in accordance with the grid regulations. Such a system could make it possible for consumers to install solar arrays on roof-tops and contribute power to the grid. Another extension could be to reduce the power losses in system and improve the power transfer efficiency. Future work could also be done to develop a current maximum power point tracking (CMPPT) algorithm and integrate it to the existing algorithm. Addressing these issues can increase the efficiency of proposed system and expand its scope to other sources of energy. 


\section{REFERENCES}

[1] S. Armstrong and W. G. Hurley, "Self-regulating maximum power point tracking for solar energy systems," in Universities Power Engineering Conference, 2004. UPEC 2004. 39th International, 2004, pp. 604-609 vol. 1.

[2] S. Armstrong and W. G. Hurley, "Investigating the Effectiveness of Maximum Power Point Tracking for a Solar System," in Power Electronics Specialists Conference, 2005. PESC'05. IEEE 36th, 2005, pp. 204-209.

[3] S. L. Brunton, C. W. Rowley, S. R. Kulkarni, and C. Clarkson, "Maximum power point tracking for photovoltaic optimization using extremum seeking," in Photovoltaic Specialists Conference (PVSC), 2009 34th IEEE, 2009, pp. 000013000016 .

[4] S. L. Brunton, C. W. Rowley, S. R. Kulkarni, and C. Clarkson, "Maximum Power Point Tracking for Photovoltaic Optimization Using Ripple-Based Extremum Seeking Control," Power Electronics, IEEE Transactions on, vol. 25, pp. 2531$2540,2010$.

[5] L. Hung-Ching and S. Te-Lung, "Design of DC/DC Boost converter with FNN solar cell Maximum Power Point Tracking controller," in Industrial Electronics and Applications (ICIEA). 2010 the 5th IEEE Conference on, 2010, pp. 802-807.

[6] K. H. Hussein, I. Muta, T. Hoshino, and M. Osakada, "Maximum photovoltaic power tracking: an algorithm for rapidly changing atmospheric conditions," Generation, Transmission and Distribution, IEE Proceedings-, vol. 142, pp. 5964, 1995.

[7] K. Il-Song, K. Myung-Bok, and Y. Myung-Joong, "New Maximum Power Point Tracker Using Sliding-Mode Observer for Estimation of Solar Array Current in the Grid-Connected Photovoltaic System," Industrial Electronics, IEEE Transactions on, vol. 53, pp. 1027-1035, 2006.

[8] E. Iyasere, E. Tatlicioglu, and D. M. Dawson, "Backstepping PWM control for maximum power tracking in photovoltaic array systems," in American Control Conference (ACC), 2010, 2010, pp. 3561-3565. 
[9] N. Khaehintung, P. Sirisuk, and A. Kunakorn, "Grid-connected Photovoltaic System with Maximum Power Point Tracking using Self-Organizing Fuzzy Logic Controller," in TENCON 20052005 IEEE Region 10, 2005, pp. 1-4.

[10] R. Leyva, C. Alonso, I. Queinnec, A. Cid-Pastor, D. Lagrange, and L. MartinezSalamero, "MPPT of photovoltaic systems using extremum - seeking control," Aerospace and Electronic Systems, IEEE Transactions on, vol. 42, pp. 249-258, 2006.

[11] Y. P. Siwakoti, B. B. Chhetri, B. Adhikary, and D. Bista, "Microcontroller based intelligent $\mathrm{DC} / \mathrm{DC}$ converter to track Maximum Power Point for solar photovoltaic module," in Innovative Technologies for an Efficient and Reliable Electricity Supply (CITRES), 2010 IEEE Conference on, 2010, pp. 94-101.

[12] K. Tabaiya, W. Lenwari, and C. Prapanavarat, "A single-phase grid-connected inverter using a Boost Two-Cell Switching converter with Maximum Power Point Tracking algorithm," in Electrical Engineering/Electronics, Computer, Telecommunications and Information Technology. 2008. ECTI-CON 2008. 5th International Conference on, 2008, pp. 1001-1004.

[13] O. Yangjing, W. Chenghua, and H. Feng, "A Variable Step Maximum Power Point Tracking Method Using Taylor Mean Value Theorem," in Power and Energy Engineering Conference (APPEEC), 2010 Asia-Pacific, 2010, pp. 1-4.

[14] K. H. Hussein, I. Muta, T. Hoshino, and M. Osakada, "Maximum photovoltaic power tracking: an algorithm for rapidly changing atmospheric conditions," Generation, Transmission and Distribution. IEE Proceedings-, vol. 142, pp. 5964, 1995.

[15] J. Chen, C. Pan, and J. Wu, "Dynamic surface backstepping control design for one hypersonic vehicle," in Mechatronics and Automation, 2009. ICMA 2009. International Conference on, 2009, pp. 4770-4774.

[16] P. Pranayanuntana and V. Riewruja, "Nonlinear backstepping control design applied to magnetic ball control," in TENCON 2000. Proceedings, 2000, pp. 304307 vol.3.

[17] Daniel W.Hart, Power Electronics, McGraw-Hill Companies Inc., 2010.

[18] Dr.P.S. Bimbhra, Power Electronics, Khanna Publishers, 2006.

[19] http://www.altestore.com/howto/Solar-Electric-Power/Reference-Materials/SolarInsolation-Map-World/a43/

[20] http://atmospheres.gsfc.nasa.gov/climate/index.php?section=136

[21] http:/hww.americanenergyindependence.com/solatenergy.aspx 
[22] http://zone.ni.com/devzone/cda/tut/p/id/8106

[23] http://www.carbonenergy.co.uk/renewable-energy/solar/

[24] Perlin, John (2004). "The Silicon Solar Cell Turns 50". National Renewable Energy Laboratory. Retrieved 5 October 2010.

[25] R. Ortega, A. Lorai, P. J. Niklasson and H. Sira-Ramirez, Passivity-based Control of Euler-Lagrange Systems, London: Springer-Verlag, 1998, pp. 168-171.

[26] J. Slotine and W. Li, Applied Nonlinear Control, Englewood Cliffs, NJ: Prentice Hall, 1991.

[27] www.eere.energy.gov/solar/pv_systems.html Department of Energy, Retrieved Aug. 17, 2005. \{\{PD-USGov-DOE $\}\}$ 


\section{CURRICULUM VITAE}

NAME: $\quad$ Anvin Joe Manadan

ADDRESS: 2203 James Guthrie Ct, Apt1

Louisville, KY 40217

DOB: $\quad$ Kerala, India - February 17, 1987

EDUCATION

\& TRAINING: B-Tech, Cochin University of Science And Technology, 2009

PROFESSIONAL SOCIETIES: IEEE Student Branch 